The Relationship between Parent Perceptions of Preschooler Mealtime Behaviors and Diet Variety

Thesis

Presented in Partial Fulfillment of the Requirements for the Degree Master of Science in the Graduate School of The Ohio State University

\author{
By \\ Evelyn Koski B.S. \\ Graduate Program in Allied Medicine
}

The Ohio State University

2014

Thesis Committee:

Dr. Marcia Nahikian-Nelms, PhD, RD, LD, CNSC, Advisor

Dr. Kay Wolf, PhD, RD, LD

Dr. Sarah Anderson PhD 
Copyright by

Evelyn Koski

2014 


\begin{abstract}
Objective: To assess the most common parent concerns about their preschooler's eating habits and determine how individual child food frequencies correlate with parent perceptions of the child's diet and mealtime behaviors within a nonrandomized sample of convenience from a university day care setting.

Methods: This descriptive study surveyed parents of children ages 3-5 who were attending a large Midwestern University child care program. An adapted version of the previously validated parent-report mealtime behavior questionnaire (Meals in Our Household) was used to assess the most common types of problematic child mealtime behaviors as reported by parents, as well as parent concern regarding the child's mealtime behaviors and diet. Child's diet variety was assessed using an adapted food frequency questionnaire to determine the number of different foods within the five major food groups that were consumed over a one week period. Questionnaires were scored and the relationships were assessed using Spearman correlation coefficients.

Results: The most frequent problematic child mealtime behaviors reported by parents were that their child squirms or fidgets while eating (31\%), refuses to try new foods (31\%) and is picky about the food he or she will eat (37\%). When relationships were assessed, there appeared to be no significant correlation between parental concern about mealtime behaviors and the total number of foods consumed by the child $(\mathrm{r}=.084$,
\end{abstract}


$\mathrm{p}=.550)$. Similarly, parent concern about child's diet was not correlated with the total number of foods consumed by the child $(r=.005, \mathrm{p}=.968)$.

Conclusions: These findings suggest that parent concern about their child's diet and mealtime behaviors may not be appropriate measures of the quality and variety of the child's diet. Clinicians should not simply rely on broad overall nutrition questions to assess the child's eating habits and more specific questioning and additional assessment methods may be necessary to properly assess the child's behaviors and diet variety. 


\section{Acknowledgments}

First I would like to thank my advisor, Dr. Marcia Nahikian-Nelms, for her continuous support and encouragement over the past two years. Without her expertise and dedication this thesis would not have been possible. I would also like to thank my other committee members, Dr. Kay Wolf and Dr. Sarah Anderson for the knowledge, input and guidance they have provided me with throughout the thesis process.

Additionally, I would like to thank Jean Dodson and the Ohio State Child Care Program staff for allowing me to conduct my research at their site and for their assistance and support during my data collection. 


\section{Vita}

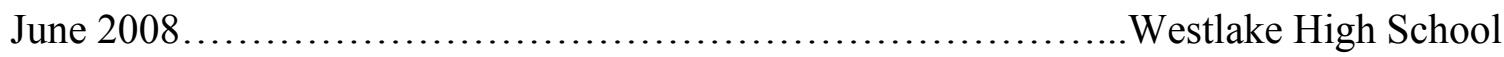
June $2012 \ldots \ldots \ldots \ldots \ldots \ldots \ldots \ldots \ldots \ldots \ldots \ldots \ldots \ldots \ldots \ldots \ldots$.S. Dietetics, The Ohio State University August 2012 to present.................Combined MS/DI Program in Medical Dietetics, The Ohio State University

Field of Study

Major Field: Allied Medicine 


\section{Table of Contents}

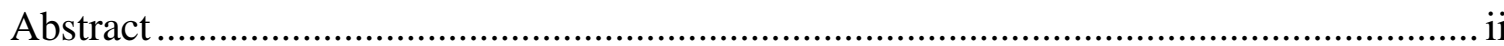

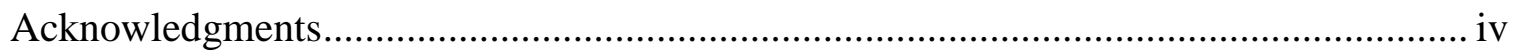

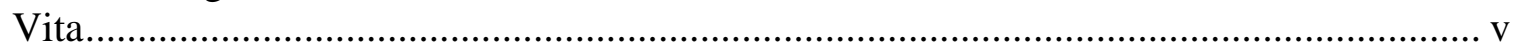

List of Tables .................................................................................................. viii

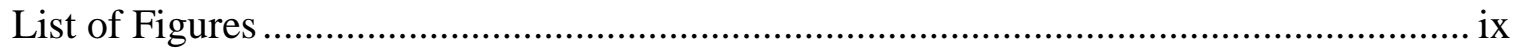

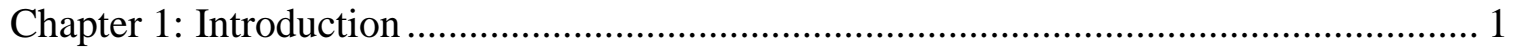

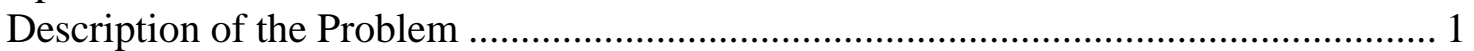

Statement of the Problem ........................................................................................... 2

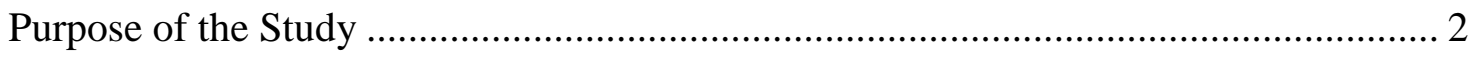

Research Objective....................................................................................... 2

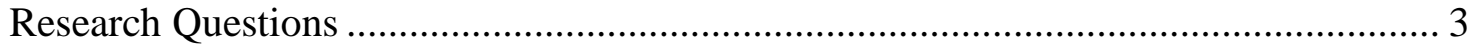

Significance of the Study ..................................................................................... 3

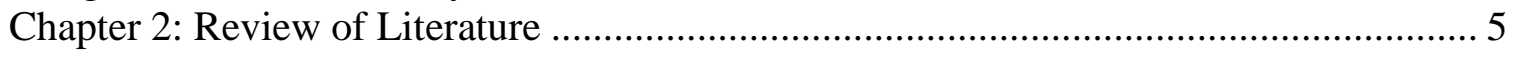

Development of Food Preferences in Children ................................................. 5

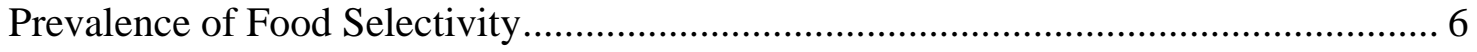

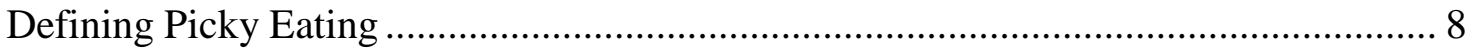

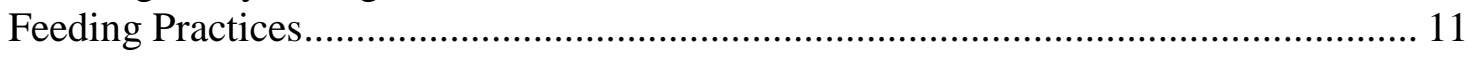

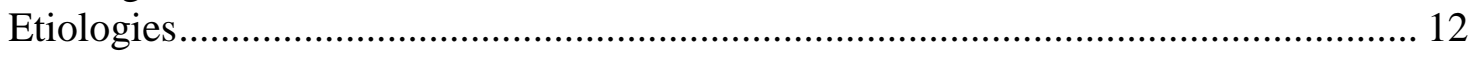

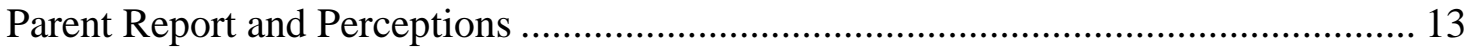

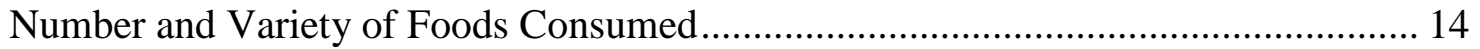

Long-Term Effects ....................................................................................... 17

Assessment of Feeding Practices and Mealtime Behaviors ...................................... 18

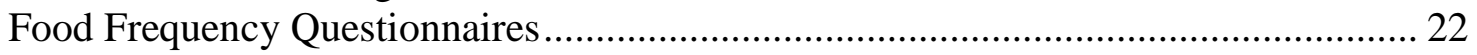

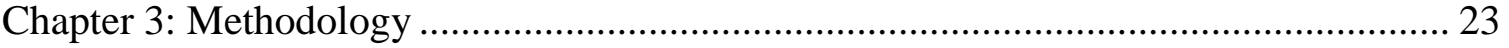

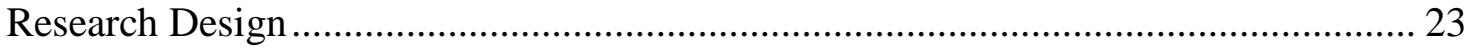

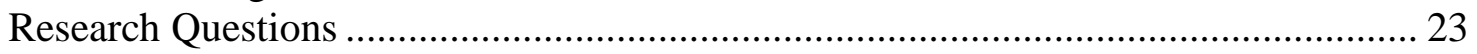

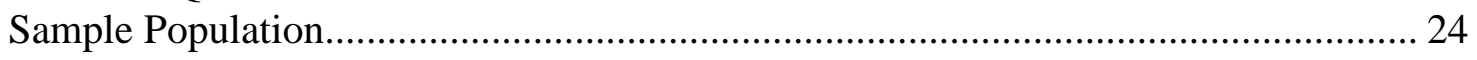

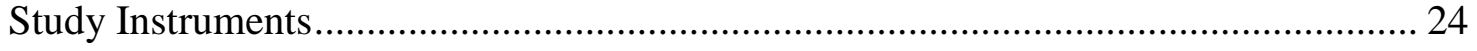

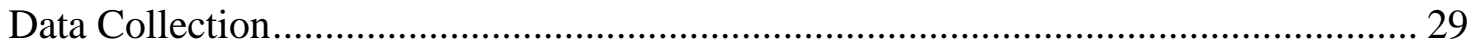

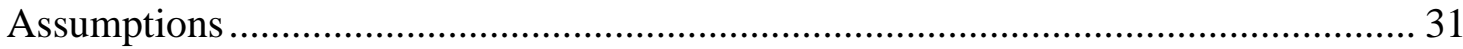

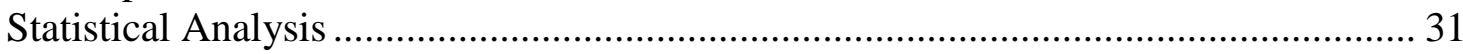

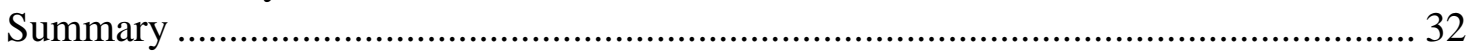

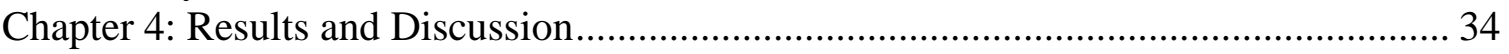

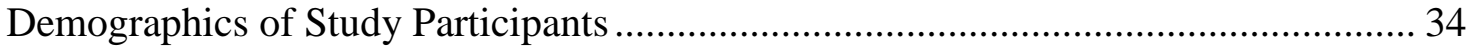

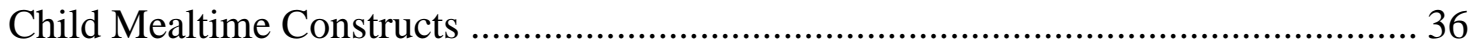

Occurrence of Problematic Mealtime Behaviors ...................................................... 38

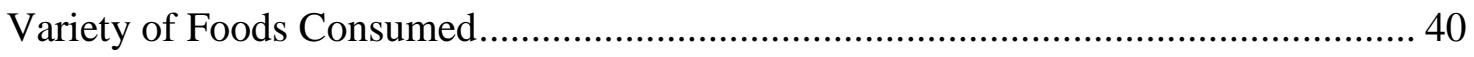

Relationships between Parent Concern and Diet Variety ........................................ 42 
Relationships between Child Mealtime Constructs .................................................... 44

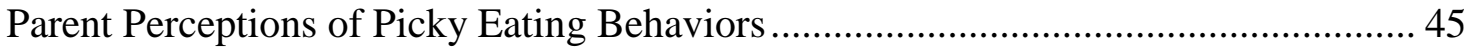

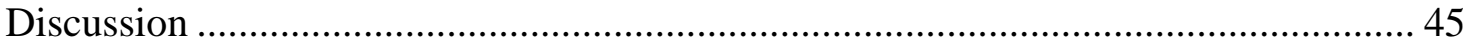

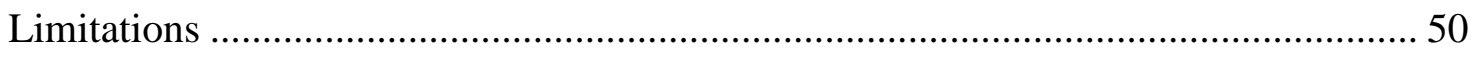

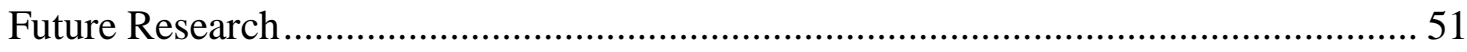

Chapter 5: The Relationship between Parent Perceptions of Preschooler Mealtime

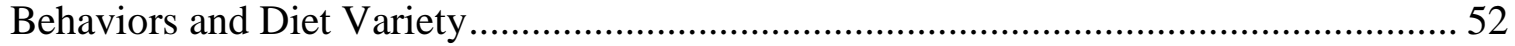

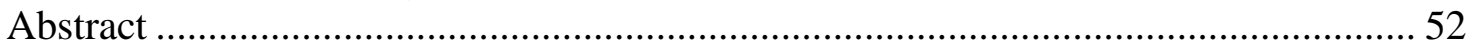

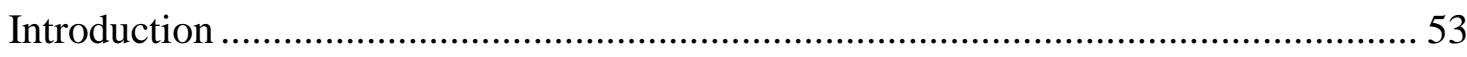

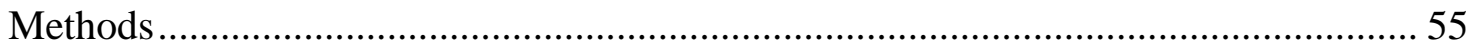

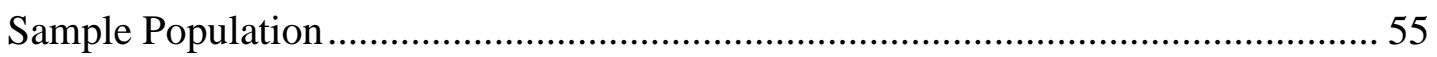

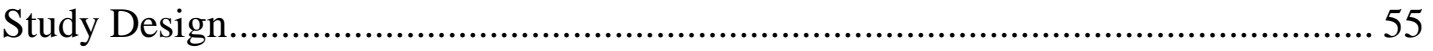

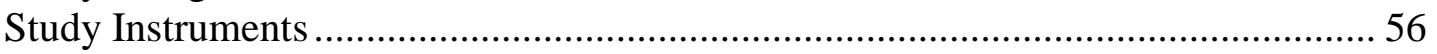

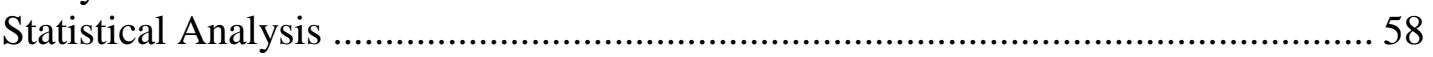

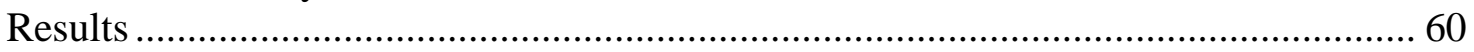

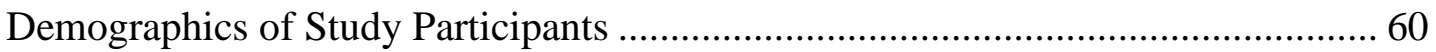

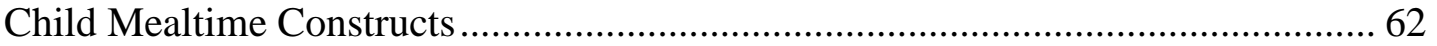

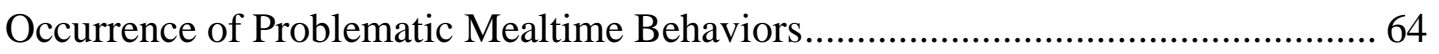

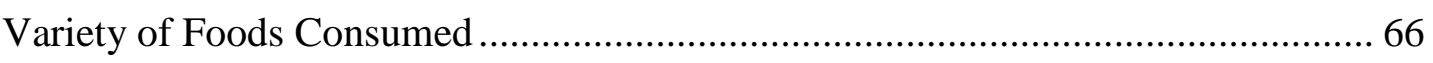

Relationships between Parent Concern and Diet Variety.......................................6 67

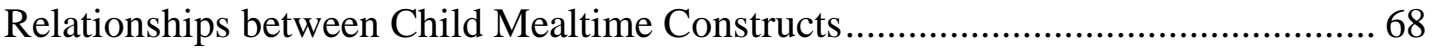

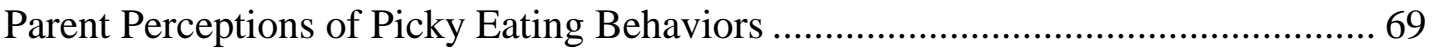

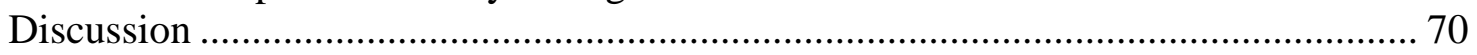

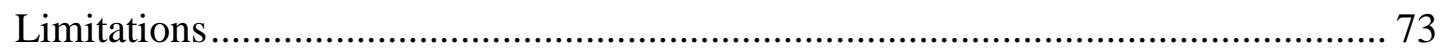

Implications for Research and Practice ........................................................... 74

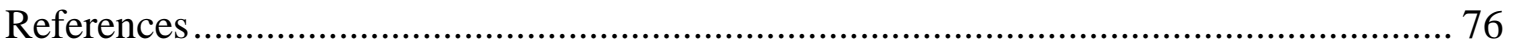

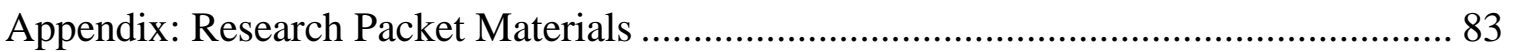




\section{List of Tables}

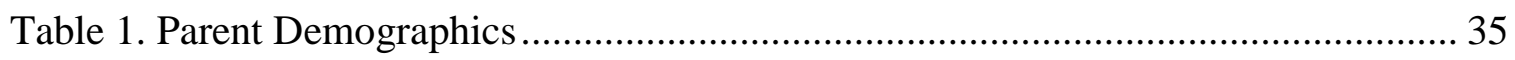

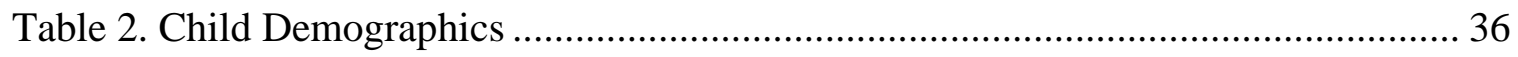

Table 3. Descriptive Statistics of Mealtime Construct Scores..................................... 37

Table 4. Correlational Analysis of Weekly Number of Foods Consumed and Child Mealtime Using Spearman Correlation Coefficients ............................................... 43

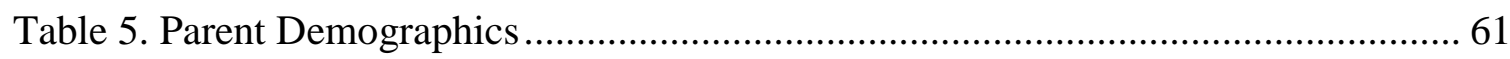

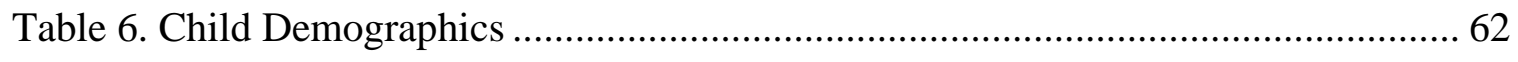

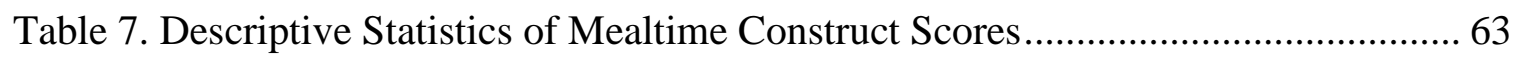

Table 8. Correlational Analysis of Weekly Number of Foods Consumed and Child Mealtime Constructs Using Spearman Correlation Coefficients ................................ 68 


\section{List of Figures}

Figure 1. Occurrence of Problematic Mealtime Behaviors ......................................... 39

Figure 2. Frequency of Behaviors Reported to Occur Often/Very Often ....................... 40

Figure 3. Mean Number of Foods Consumed Weekly by Child Demographics ............. 41

Figure 4. Occurrence of Problematic Mealtime Behaviors ........................................ 65

Figure 5. Frequency of Behaviors Reported to Occur Often/Very Often ....................... 66

Figure 6. Mean Number of Foods Consumed Weekly by Child Demographics .............. 67 


\section{Chapter 1: Introduction}

\section{Description of the Problem}

Food selectivity or "picky eating" is common in young children and can create a stressful environment at family mealtimes. Between $25-35 \%$ of children in the United States are considered picky eaters and that statistic increases in those with chronic medical conditions. ${ }^{1}$ Picky eating most commonly occurs during early childhood when food preferences and eating habits are being established. ${ }^{2-4}$ It is during this time period that food preferences are shaped which may impact eating habits for the rest of the child's life.

Previous research has attempted to define picky eating using various definitions, but the wide variety and complexity of feeding problems in children has caused discrepancies in the subsequent definitions and classifications. Past definitions have typically focused on either limited variety of food choices or a limited volume of food

consumed. Current research has used these definitions and incorporates numerous other characteristics to describe picky eating. ${ }^{5,6}$ Parent report is one of the most common methods used to assess eating behaviors in early childhood and therefore, picky eating descriptions typically rely on this as the method for data collection. The most common behaviors reported by mothers in regards to picky eating include consumption of a limited number and variety of foods, unwillingness to try new foods, strong food 
preferences and dislikes, requiring specific food preparation and presentation, and having long lasting mealtimes. ${ }^{5,7-10}$

Children with picky eating behaviors, especially those with limited food intake or decreased variety of foods, are at risk for both short and long term health consequences. In order to limit the health risks, steps to improve the child's eating habits and feeding environment should begin as soon as possible. Unfortunately, standardized diagnostic and treatment methods do not exist which may impact the ability to treat.

\section{Statement of the Problem}

Although numerous studies have conducted research regarding picky eating and other feeding disorders, no standardized methods or definitions for classification exist. ${ }^{7,10-15}$ The lack of a standard definition of "picky eating" has made it difficult for parents, teachers and clinicians to effectively communicate about children's feeding problems. This can lead to discrepancies in diagnosis and treatment among health professionals in this field. Because there are no standardized criteria, health professionals must often rely on parent report to judge feeding problems in children.

\section{Purpose of the Study}

The purpose of this study was to further examine the description of picky eating by assessing parent perceptions of preschool children's mealtime behaviors and eating habits. Secondly, this study assessed how parent concerns correlate with the child's diet variety as measured by a food frequency questionnaire.

\section{Research Objective}


The objective of this study was to assess the most common parent concerns about their preschooler's eating habits and determine how individual child food frequencies correlate with parent perceptions of the child's diet and mealtime behaviors within a nonrandomized sample of convenience from a university day care setting.

\section{Research Questions}

1. In a sample of parents with children attending a university child care program what are the most frequent problematic child mealtime behaviors reported by parents?

2. Is there a relationship between parental concerns about their child's diet and the variety of foods consumed by the child?

3. Is there a relationship between parental concerns about their child's mealtime behavior and the variety of foods consumed by the child?

\section{Significance of the Study}

Most children will exhibit some form of picky eating during early childhood as a normal component of child development. This is often expressed as the desire to exert their growing independence at mealtimes. Many children will "grow out" of this stage, but some children's picky eating habits may continue to develop into a feeding disorder

that can result in malnutrition with subsequent long-term health consequences. ${ }^{16-18}$ Researchers have studied these feeding disorders in an attempt to develop diagnosis and treatment methods, but no standardized intervention has been developed. Because diagnosis and classification of feeding problems continue to be disputed, health professionals rely heavily on parent reports of their child's eating habits and behaviors. 
This study will examine parent concerns regarding their child's diet and mealtime behaviors and the correlation of these concerns with individual food frequencies to assess the reliability of parent report of their child as a picky eater. 


\section{Chapter 2: Review of Literature}

This literature review examines research in regards to typical preschool mealtime behaviors and how they relate to the various definitions of picky eating, as well as parent perceptions of their child's eating habits. It will also include current research in the diagnosis and treatment of food selectivity and any potential health consequences.

\section{Development of Food Preferences in Children}

Past research has determined that food preferences are shaped by numerous exposures to foods, the physiological outcomes of eating, and the social context

surrounding mealtime..$^{2-4,19-22}$ Because young children are constantly being introduced to new foods, it is a normal behavior for children to initially reject unfamiliar foods. This fear of new foods is termed food neophobia and is related to the innate fear of the potential risks of ingesting a new food. Research has demonstrated that an organism is programmed to fear that a new food is toxic and could cause negative consequences such as illness or even death. ${ }^{23,24}$ Although this neophobia is typical for all children, it has been shown that repeated exposure to foods usually increases the child's acceptance of that particular food and similar foods. Research shows that it typically takes ten to fifteen exposures for a food to be accepted. ${ }^{19,25-28}$

In addition to increased exposure, the physiological changes that result after eating can play a major role in children's development of food preferences. For example, if a negative gastrointestinal event such as nausea or vomiting results from consuming a 
certain food, an aversion to that food may result. However, when a food results in positive feelings of satiety a learned food preference can develop. ${ }^{3}$ Because eating is usually a social event, similar reactions can be caused by the social context in which food is eaten. If foods are consumed in a positive context with family or friends, children may be more likely to eat foods that others are eating and the food may become a learned preference. ${ }^{20}$ Whereas if a food is consumed in a negative context, such as being pressured or forced to eat, negative effects on food intake and food aversions may result. ${ }^{29}$ In addition, the positive association of having regular family mealtimes has been associated with increased diet quality in children. ${ }^{30,31}$

It is also important to consider the possible effects of providing food as reward for performing a requested behavior or consumption of a requested food. According to Birch and Fisher (1995), foods that are eaten as a dessert or on special occasion will typically become more preferred. ${ }^{3}$ When this preferred food is used to reward the child for consuming a novel food, preference for the novel food usually declines.

\section{Prevalence of Food Selectivity}

A child's food preferences are developed before age 5 and can have a significant impact on eating habits throughout their lifetime. ${ }^{22,32}$ Picky eating most commonly occurs during this crucial period of early childhood and although the majority of cases decline with age, more severe cases can continue through adolescence and even adulthood. ${ }^{7,9,11,33}$ Additional research has found a correlation between picky eating in early childhood and similar eating behaviors in preadolescence. More specifically, they have shown that 
picky eating does not decrease with age and that levels of food repertoire and food refusal are equally prevalent during preadolescence. ${ }^{7,12}$

The reported prevalence of picky eating varies among studies, but is typically between $25-35 \%$ of all children and $40-80 \%$ in the developmentally disabled. ${ }^{1,11,18,34} \mathrm{~A}$ limited body of research exists in this area, but it has been recognized that having a developmental disability increases the risk of developing feeding problems as well as problematic mealtime behaviors. Any developmental disorder could cause problematic mealtime behaviors or feeding problems, but the most common disorders linked to feeding problems are Autism Spectrum Disorders, Down Syndrome and Cerebral Palsy. ${ }^{34}$ Particular attention should be directed to children with Autism Spectrum Disorders (ASD) as a growing body of research shows a significant relationship between children with ASDs and food selectivity. ${ }^{12,35-39}$ Typically children with ASDs are described as having unusual eating habits including rigid mealtime behaviors and extreme food selectivity with aversions to foods based on specific texture, color, smell, temperature. $^{12,37}$

Past research on food selectivity has found that picky eating behaviors are prevalent among children regardless of age, gender, ethnicity and socioeconomic status. ${ }^{40,41}$ Some research has suggested that the prevalence of feeding problems is greater in males than females, but this difference does not seem to be large. ${ }^{7,11}$ However, the type of food preferences between genders do differ significantly. One study conducted by Cooke and Wardle (2005), found that girls had a stronger preference for fruits and vegetables, whereas boys preferred foods with higher fat and sugar, meats, processed 
meats and eggs. ${ }^{42}$ In regards to ethnicity and socioeconomic status, Evans, et al. (2011) found that parents with higher-income were more likely to believe their children are picky eaters than WIC participants. ${ }^{43}$ This suggests that children of higher socioeconomic status are more likely to be recognized as picky eaters, but should not imply that the actual prevalence is higher.

A recent study conducted by Hafstad, Abebe, Torgersen \& von Soest (2013), found that having siblings at a young age can be protective against developing food selectivity. ${ }^{44}$ This may be due to the social interaction and modeling behaviors conducted by the older siblings during mealtime. It could also be due to decreased parental focus on the younger child which provides the child with more freedom and less feeling of pressure to eat. This may be valuable since pressure to eat has been shown to increase picky eating during childhood. ${ }^{44}$

\section{Defining Picky Eating}

The wide variety and complexity of feeding problems in children has resulted in discrepancies in their definitions and classifications. Past definitions have typically focused on either limited variety or limited amounts of consumed food. ${ }^{5,6}$ Current research has evolved from these previous definitions and a wide variety of characteristics are used to describe picky eating.

The first discrepancy among researchers is related to the numerous terms that are used interchangeably to describe various feeding problems. Among the common terms used are food selectivity, picky eating, restrictive eating, choosy eating, chronic food refusal, food aversion, food neophobia, perseverant eating, sensory food aversion, and 
food avoidance. Although there is a long list of commonly used terms, each one is typically related to either the adequacy of overall diet, the variety of accepted foods, or food avoidance. ${ }^{10,14}$

There are also multiple diagnostic criteria that are used to identify feeding disorders in children. The Diagnostic and Statistical Manual of Mental Disorders $\left(5^{\text {th }}\right.$ ed. text revision, DSM IV-TR) described feeding disorders of infancy or early childhood as a persistent feeding disturbance and either a failure to gain weight or a significant loss of weight for at least one month without significant medical conditions or lack of available food. ${ }^{45}$ Some researchers and clinicians have used these criteria, but many have argued that it does not encompass all of the pediatric feeding problems that exist. The recently published $5^{\text {th }}$ edition, DSM-V, has changed the title from feeding disorder of infancy or early childhood to avoidant/restrictive food intake disorder. ${ }^{46}$ The criteria have been broadened to incorporate all ages and the wide range of feeding disorder presentations. The DSM-IV disorder was rarely used, but information has yet to be determined regarding the new criteria. Recent studies have suggested different criteria for diagnosing and categorizing feeding disorders, but none has been adopted as a standard. ${ }^{15,47,48}$ Burklow, Phelps, Schultz, McConnell \& Rudolph (1998) created a classification system for children with complex feeding problems that attempted to include those of mixed etiologies. ${ }^{47}$ All of the children in this study had been referred to an interdisciplinary feeding team for poor oral intake or problems with sustaining growth. The team developed five different groups that they believed could categorize the complex feeding disorder. They included: structural abnormalities, neurological conditions, 
behavioral issues, cardiorespiratory problems, and metabolic dysfunction. Burklow, et al. (1998) found that $85 \%$ of the children participating in the study fit into two to four of the categories. This study demonstrates the complexity of categorizing and diagnosing pediatric feeding disorders.

In 2009, Kerzner developed a guide for pediatricians to screen for feeding problems in young children by utilizing what he calls "red flags" that implicate organic disease. ${ }^{48}$ His method begins with obtaining the child's history and anthropometric measurements and conducting a physical exam in order to identify any red flags. Any sign or symptom that suggests an underlying medical condition such as odynophagia, difficulty swallowing, crying during feeding, vomiting and diarrhea, eczema, failure to thrive, and developmental disabilities would be considered a red flag. If treatment has been administered for the organic problem and the child still remains difficult to feed, additional information regarding the details of feeding practices, problematic behaviors, and parent-child feeding interaction should be obtained. Kerzner suggests when all this prior information is obtained. The nature of the feeding problem can be determined and the child can be classified into one of four categories: limited appetite (4 subtypes), highly selective intake, crying interferes with feeding (colic), or fear of feeding. ${ }^{48}$

Dovey, Farrow, Martin, Isherwood \& Halford (2009), suggested food refusal behaviors can be separated by behavioral and observable characteristics into five distinct categories. ${ }^{15}$ These categories include: selective food refusal, fear-based food refusal, medical complications food refusal, learning dependent food refusal, and appetiteawareness-autonomy-based food refusal. Based on the pathology of the feeding disorder, 
different intervention methods should be initiated. Similar to the research conducted by Burklow, et al. (1998), Dovey, et al. (2009) suggests that feeding behaviors can be classified into these five categories, they can often occur alongside developmental disabilities or behavioral disorders which makes classification and intervention more difficult.

\section{Feeding Practices}

A recent study conducted by Benjasuwantep, Chaithirayanon \& Eiamudomkan (2013), looked at the feeding practices of children with feeding problems in comparison to those without and found that there were significant differences among them. ${ }^{11}$ They used Kerzner's description of feeding difficulties to assess whether or not children should be categorized as having feeding problems. ${ }^{48}$ Children with feeding problems were fed less frequently, were less likely to be fed at a an appropriate site (highchair, child's table or family table), did not have a regular site for feeding and their meal times typically lasted longer than 30 minutes. ${ }^{11}$

Faith, Storey, Kral \& Pietrobelli (2008) developed a questionnaire to assess parent beliefs about how their child should be eating. ${ }^{49}$ They found that maternal frustration with child eating corresponds with greater pressure on children to eat and that maternal demand regarding the amount of foods is associated with greater feeding restriction and pressure to eat. Additionally, Faith, et al. (2008) found that more demands regarding the amount of food eaten are placed on children by younger mothers as opposed to older mothers. Research conducted by Galloway, Fiorito, Francis \& Birch (2006) found that pressuring a child to eat may increase initial intake, but will typically have negative 
effects on the future intake and preference for a food. ${ }^{44}$ Similarly, Hafstad, et al. (2013) found that mothers with negative affect (measured by levels of anxiety and depression), fearfulness and distress can have long-term negative consequences on the development of the child's eating habits. ${ }^{50}$ Because parents of picky children are more likely to be concerned and/or develop frustration with their child's eating habits, they may also be the parents that are likely to pressure their children to eat. This in turn can have the opposite effect and contribute to even greater problem behaviors while lowering total intake and causing negative emotional responses to food.

\section{Etiologies}

The progression of normal feeding and eating behaviors in a child is dependent on numerous aspects of development and if any are inhibited or delayed, feeding problems may occur. According to Fishbein, et al. (2006) mild feeding disorders are described as having a tendency to avoid certain foods related to taste, texture, appearance or smell. ${ }^{51}$ Severe feeding disorders are described as an extreme restriction of foods that may negatively affect nutritional status. ${ }^{51}$ This wide range in severity of feeding disorders is most likely related to the diversity of potential etiologies. These include medical, nutritional, behavioral, psychological and environmental factors. ${ }^{14,18}$

Feeding disorders can be caused by organic or nonorganic (functional) factors. Physical and metabolic abnormalities are considered organic factors, whereas functional factors involve environmental causes. ${ }^{52}$ Medical causes are considered organic factors and can include low oral muscle tone, oral motor dysfunction, anatomical abnormalities, muscular disorders, and chronic or recurring gastrointestinal problems. ${ }^{13,14}$ In addition, 
developmental disabilities such as ASD, Down Syndrome and Cerebral Palsy are often associated with feeding problems. ${ }^{34}$ Functional factors are related to psychological and behavioral aspects in correlation with the environment. These can include a response to a traumatic feeding event, sensory issues, food aversions and phobias, child behavior problems, and negative parental behaviors regarding feeding. ${ }^{13,14}$

The majority of feeding disorders during childhood involve both organic and functional factors. ${ }^{18,41,52,53}$ Budd, et al. (1992) found that $26 \%$ of feeding disorders were attributable to organic factors, $10 \%$ were due to functional factors and $64 \%$ were a result of both. ${ }^{53}$ The variety of feeding and eating problem etiologies, in addition to a lack of standardized definition, makes diagnosis and treatment of feeding disorders difficult. Depending on the etiology intervention treatment methods can widely vary and all aspects should be considered.

\section{Parent Report and Perceptions}

Picky eating is a common problem stated by parents of young children and although many children will improve their eating habits with age, many will have problematic mealtime behaviors that continue or even become worse. Approximately one fifth of parents of toddlers perceive their child as having an eating problem, with the most common problem reported being a lack of variety in foods and preference for drinks rather than solid food. ${ }^{54}$

A past study conducted by Dubois, Farmer, Girard \& Peterson (2007) assessed the relationship between eating behaviors and dietary adequacy in preschool children. ${ }^{55}$ Eating behaviors were evaluated by self-administered parent report questionnaires and 
nutrition data was collected using one 24-hour recall. Mother's perceptions of their child's eating behaviors were classified into three groups: picky eaters, irregular eaters and overeaters. Diet adequacy was evaluated using the Canadian Nutrient File and the USDA recipe file. Dubois, et al. (2007) found that preschool children are either under- or over-consuming some food groups. This research described that picky eaters were consistently consuming less total energy, fewer fats and protein than children with normal eating behaviors. ${ }^{55}$ This was also one of few studies that found a positive association between the diet adequacy of preschool children and their mother's perceptions regarding their eating behaviors. Children of mothers who reported more frequent picky eating behaviors appeared to have poorer diets than those that did not.

Common behaviors reported by mothers in regards to picky eating include consumption of a limited number and variety of foods, unwillingness to try new foods, strong food preferences and dislikes, requiring specific food preparation and presentation, and having longer lasting mealtimes. ${ }^{5,7-10}$ Jacobi, Schmitz, Agras (2008) stated that these problem behaviors were linked to more mealtime struggles and feeding difficulties in comparison to non-picky eaters. ${ }^{7}$ This study as well as others, have shown that parents of picky eaters are more likely to offer food as a reward, prepare separate meals for the child, and allow television during meals than their non-picky counterparts..$^{7-9}$

\section{Number and Variety of Foods Consumed}

As previously stated, one of the most common behaviors related to picky eating reported by mothers is the consumption of a limited number and/or limited variety of foods. ${ }^{5,-9}$ Although, past research has shown these to be commonly reported by parents, 
very few studies have assessed the actual number of foods consumed by the child. However, multiple studies have used the number of foods preferred by the child to assess diet. $^{39,42,54}$

Cooke and Wardle (2005) conducted a study to assess food preferences in children ages 4-16 years old. ${ }^{42}$ Children completed a self-reported food preference questionnaire with 115 items. They were to mark whether or not they had ever tried the food, and if so, how much they liked it. Although this study assessed food preferences as opposed to number of foods consumed, it is important to consider because it provides a picture of the number of foods preferred by children. They found that the number of foods tried by children increased strongly with age, but the number of foods children liked decreased with age. They suggest that although children's neophobia may decrease with age, the actual liking of new foods may not increase. ${ }^{42}$

Similarly, Wright, Parkinson, Shipton, \& Drewett, (2006), conducted a study to examine eating behaviors and their mother's approach to feeding. ${ }^{54}$ Additionally, they assessed the prevalence of eating problems perceived by parents and their relationship with certain behaviors, food preferences and growth in the child. Food preferences were assessed using a modified food preferences questionnaire that listed 89 foods and types of food that parents were to rate their child's liking of the food. They found the median number of foods tried to be 70 (range of 20-90) and the median number of foods liked was 52 (range of 14-82). Children who were reported to have eating problems or to be "faddy" (picky) were shown to like a significantly smaller number of foods. ${ }^{54}$ 
Williams, Hendy \& Knecht (2008) studied the dimensions of feeding practices used by parents of children ages 2-8 year who were referred to a multidisciplinary clinic for feeding problems. They then compared these with child variables as predictors of weight status, diet variety, and mealtime behavior problems. To assess diet variety parents were provided a list of 139 common foods and asked to report whether or not their child would consume each of them. The mean number of foods reported was used as their diet variety and the mean number of foods was $26 \pm 20.4$. They found that many of the children with lower diet variety were the children diagnosed with Autism and whose parents were more likely to become permissive. In this study, parents were considered likely to become permissive if they were allowing foods in between meals, giving the child alternative food options than those served, and not encouraging daily fruit and vegetable consumption. All of which were suggested to have a negative impact on diet variety by decreasing appetite at mealtimes and limited exposure to novel foods. ${ }^{39}$

Carruth, et al. (1998) studied the variety and diversity of toddler's diets by calculating a score for each based on parent reported food intake. ${ }^{5}$ To assess whether mother's considered their child to be a picky eater they used a questionnaire about picky eating behaviors. They assessed the relationship between the mother's perceptions and the dietary variety and diversity scores and found that children perceived to be picky eaters by their mothers had a lower dietary variety and diversity than children perceived as non-picky eaters. ${ }^{5}$ 


\section{Long-Term Effects}

In recent studies, significant correlations have been found between picky eating behaviors and nutritional deficits related to their low consumption of fruits, vegetables, meat and fiber sources. ${ }^{27,55-57}$ Children with picky eating behaviors leading to nutrient deficiency are at risk for health consequences including reduced energy, heightened susceptibility to illness, growth retardation, emotional dysfunction, cognitive impairment, malnutrition and even death. ${ }^{18,58-61}$ Malnutrition during early childhood has negative long-term effects. Recent studies conducted by Liu, Raine, Venables \& Mednick (2004) and Liu and Raine (2006) showed that malnutrition in early childhood predisposes children to externalizing behavior problems such as aggression, hyperactivity, and conduct disorder and that if not treated properly can continue throughout childhood and adolescence. ${ }^{17,58}$ This supports early research by Barret, Radke-Yarrow \& Klein (1982) that malnutrition during early years of life can negatively impact social and emotional development later in life. ${ }^{60}$

Ekstein, Laniado \& Glick (2010) assessed heights and weights of children who were referred to a Pediatric Feeding and Nutrition Clinic for picky eating behavior. ${ }^{62}$ Their study aimed to find if picky eating behavior in young children is correlated with being underweight. In comparison to a control group of healthy eating children, they found a strong correlation between picky eating behaviors and underweight status. ${ }^{62}$ This association is in agreement with the findings of multiple other studies. ${ }^{40,55,56}$ Underweight during childhood may have possible long-term effects such as delayed motor and 
cognitive development, long-term behavioral problems, increased prevalence and severity of infection and high mortality rates. ${ }^{61}$

However, recent studies have found evidence that contrasts with this previous research and has shown that children with feeding disorders can be of normal, healthy weight. ${ }^{39,63}$ This may be attributable to the fact that many children with chronic medical problems that are seen as picky eaters consume diets high in calorie dense foods and parents may provide them with special meals or nutritional supplements. ${ }^{39,64,65}$

Eating problems in early childhood may also pose a risk for developing more serious eating disorders in adolescence, such as bulimia nervosa and anorexia nervosa. A longitudinal study conducted by Marchi and Cohen (1990) found a strong correlation between picky eating and digestive problems in early childhood and the development of anorexia nervosa during adolescence. ${ }^{33}$ Distress and arguing during family mealtimes during early childhood was also shown to increase rates of food avoidance later in life. ${ }^{33}$

\section{Assessment of Feeding Practices and Mealtime Behaviors}

As discussed throughout this review, because no standardized diagnostic methods have been established for picky eating, there are differing perspectives causing inconsistencies in diagnostic criteria and treatment methods. Numerous tools and instruments have been developed by researchers in attempt to identify at risk children for feeding problems and mealtime behaviors.

The Child Feeding Questionnaire (CFQ) was developed by Birch, et al. (2001) as a self-report measure for parents of normal developing children to assess parental beliefs, perceptions, and practices regarding child feeding, with a particular focus on childhood 
obesity. ${ }^{66}$ It is one of the most widely known measures and is based on the 1985 model designed by Costanzo and Woody. ${ }^{67}$ The CFQ includes questions to measure seven different dimensions that include factors regarding parent perceptions of weight (both parent and the child) and parental attitudes regarding control and feeding practices.

Faith, et al. (2008) used the ideas of the CFQ to form an additional questionnaire, The Feeding Demand Questionnaire, to measure parental demand cognitions concerning child eating. ${ }^{49}$ The Feeding Demand Questionnaire is made up of eight items to assess parental beliefs that children should comply with parental rules regarding eating with respect to both the type and amount of food consumed. In addition to the Feeding Demand Questionnaire, Faith, et al. (2008) used the CFQ to evaluate parental feeding styles, the Fear of Fat scale to measure beliefs about being overweight, and the Center for Epidemiological Centers of Depression Inventory (CES-D) to assess current depressive symptoms. Their research found that mothers who reported greater anger/frustration during feeding were more likely to pressure their children to eat, whereas mothers who reported greater demands about the amount of food their children eat were more likely to restrict eating, pressure children to eat, and to monitor their fat intake.

The Children's Eating Behavior Questionnaire (CEBQ) is a parent report questionnaire that was created by Wardle, Guthrie, Sanderson \& Rapoport (2001) to assess different eating styles in children. ${ }^{68}$ The constructs of the CEBQ were developed from the past literature on eating behavior and include: satiety responsiveness, responsiveness to food cues/external eating, emotional eating, general interest in eating, speed of eating, and food fussiness. They found a decrease in satiety responsiveness and 
slowness in eating and an increase in enjoyment of foods and food responsiveness from age 3 to 8 . The CEBQ was recently used in a study by Tharner, et al. (2014) in which they aimed to describe the characteristics of picky eaters. ${ }^{69}$ Their description was similar to past studies in that picky eaters seem to have high food fussiness, slowness in eating, and satiety responsiveness in combination with low enjoyment of food and food responsiveness.

The Parent Mealtime Action Scale (PMAS) was developed by Hendy, Williams, Camise, Eckman \& Hedemann (2009) to asses mealtime behaviors used by parents. ${ }^{70}$ The PMAS differs from past measures in that it focuses on parent behaviors during mealtime as opposed to attitudes and beliefs. It is a 31-item questionnaire that measures nine dimensions of parent mealtime behaviors. The PMAS also assesses parent and child gender differences related to parent actions during mealtime, as well as the correlation between parent mealtime actions and the child's diet and weight. Hendy, Williams, Riegel and Paul (2009) conducted a study using the PMAS to assess parent mealtime actions that mediate associations between children's fussy-eating and their weight and diet. ${ }^{63}$ Fussiness was measured using the fussiness subscale of the CEBQ and parent mealtime actions were measured using the PMAS. Diet variety of food acceptance was measured by having parents report whether or not their child would eat foods from a list of 139 common foods. They found that many of the children who were fussy eaters and consumed a limited variety of foods were still at a normal, healthy body weight. This may be explained by parents cooking them special meals (meals different from the rest of 
the family). Although special meals may improve their child's overall food consumption and BMI, it may also contribute to their limited variety. ${ }^{63}$

Crist and Napier-Phillips (2001) used a parent report measure entitled, Behavioral Pediatrics Feeding Assessment Scale (BPFAS) to gather information about the differences in the type and frequency of mealtime behaviors between children with feeding problems and normal children. ${ }^{41}$ The BPFAS is a standardized questionnaire that includes 35 items; 25 items describe possible child behaviors and 10 items assess the parent feelings regarding the problems and strategies for dealing with them. They found that children with feeding problems engaged in similar patterns of mealtime behaviors as normal children, but at a much greater frequency. In their study, younger children were more likely to whine, cry, tantrum, or spit out food, whereas the older children were more likely to get up from the table during meals, try to negotiate what will be eaten, and will request "junky, snack foods" after the meal. . ${ }^{41}$

The Meals in Our Household Questionnaire was developed by Anderson, Must, Curtin and Bandini (2012) to assess family mealtime environments and child mealtime behaviors of both typically developing and children with developmental disabilities ages 3-11. ${ }^{71}$ Meals in Our Household is a parent-report questionnaire that measures mealtime across six domains to assess the structure and environment of family meals, children's mealtime behavior and its influence on other family members, parental concern about child's diet and the use of food as a reward. ${ }^{71}$ They found that children with autism spectrum disorders had significantly higher median scores reported by parents in the 
domains regarding child mealtime behavior, parental concern about child's diet, the use of food as a reward, and spousal stress related to child's mealtime behavior. ${ }^{71}$

\section{Food Frequency Questionnaires}

It can be challenging to measure quality and variety of diet in young children because of the constant changes in their eating habits. Typically, parent report is the main source of information for preschool children's mealtime behaviors and dietary intake. This presents challenges for accuracy and reliability. The food frequency questionnaire (FFQ) is a commonly used method to assess diet over a period of time in adults and if adapted appropriately can be used in children. For toddlers and younger children, the majority of studies support the use of parental report FFQ for diet assessment. ${ }^{72-76}$

Parrish, Marshall, Krebs, Rewers \& Norris (2003) collected data on diets of children ages 1-3 years by using multiple 24 -hr recalls with parents and a parent reported FFQ. ${ }^{72}$ They found the FFQ to be in relative correlation with the 24-hr recalls. This study suggests that the parent report FFQ can be used in children as young as 1 year and is a valid way to collect data on children's diets.

There are multiple advantages to using a food frequency questionnaire including that it takes a short time to complete, does not require a highly trained interviewer, can be self-administered and it is a cost effective way to monitor individual dietary intake and variety in large studies. ${ }^{77}$ However, if too many food choices are provided it can lead to overestimation of consumption. 


\section{Chapter 3: Methodology}

\section{Research Design}

The purpose of this study is to determine how individual child food frequencies correlate with parent perceptions of child's diet and mealtime behaviors. The research design was a descriptive study and data was collected using the Meals in Our Household (MOHQ) parent report questionnaire and a modified food frequency questionnaire (FFQ). ${ }^{71}$ The MOHQ examines family mealtime environments and problematic mealtime behaviors that are common among preschool age children, as well as parent perceptions and concerns of their child's behaviors and diet. The FFQ assessed the child's usual diet and the frequency of foods they consume. This was compared to the results of the MOHQ to assess the correlation between parent perceptions and individual food frequencies.

\section{Research Questions}

1. In a sample of parents with children attending a university child care program what are the most frequent problematic child mealtime behaviors reported by parents?

2. Is there a relationship between parental concerns about their child's diet and the variety of foods consumed by the child?

3. Is there a relationship between parental concerns about their child's mealtime behavior and the variety of foods consumed by the child? 


\section{Sample Population}

The study sample included parents of preschool children ages 3-5 attending a large Midwestern university child care program. All parents with children in this age group attending the child care program were eligible to participate and were identified by the child care program staff. The researcher was given permission from the child care program director to distribute research materials to preschool classroom teachers who then distributed them to participants. There were 167 children in the target age group enrolled in preschool classrooms at the child care center at the time the study was conducted. All parents received the study materials, but participation was voluntary.

\section{Study Instruments}

The two instruments used in this study are the MOHQ and an adapted FFQ. The MOHQ is a parent-report questionnaire that is used to study family mealtime environments and children's mealtime behaviors. The questionnaire was developed for children ages 3-11 years old and measures mealtime across six domains: 1) structure of family meals, 2) problematic child mealtime behaviors, 3) use of food as a reward, 4) parental concern about child diet, 5) spousal stress related to child's mealtime behavior, and 6) influence of child's food preferences on what other family members eat. ${ }^{71}$ All items included in the questionnaire were developed by a review of literature and current instruments, as well as consultation with an interdisciplinary team of clinicians and researchers in this field. ${ }^{71}$

The six different domains were influenced by the Children's Eating Behavior

Inventory and the Behavioral Pediatric Feeding Assessment Scale. ${ }^{41,78}$ The "Structure of 
Family Meals" section includes questions regarding household meal structure and assesses the frequency of which a child is exposed to traditionally structured family meals. The "Problematic Child Mealtime Behaviors" section of questions measures how often a child expresses troublesome behaviors at mealtime and how much of a problem that behavior is perceived as by the parent. "Use of Food as a Reward" section assesses what type of situations and how often the parent uses a food to reward their child. The "Parental Concern about Child's Diet" section evaluates how the parent feels about their child's diet and what they are or are not eating. The "Spousal Stress Related to Child's Mealtime Behaviors" measures how much the parent feels the child's problematic mealtime behavior is impacting his or her spouse or partner. The "Influence of Child's Food Preferences" assesses the degree to which the child's particular food preferences affect what the rest of the family eats. For the purpose of this study these seven sections were referred to as the child mealtime constructs.

Each section of the questionnaire contained a separate Likert Scale of responses from which study participants may select from. The "Structure of Family Meals" construct included a scale ranging from "Never" to "Always or Almost Always". The construct "Use of Food as a Reward" contained a scale that ranged from "Never" to "Very Often". For the "Problematic Child Mealtime Behaviors" construct there were two separate scales. The scale for questions regarding the occurrence of problematic behaviors ranged from "Never" to "Almost Always" and for the questions regarding how much of a problem the parent perceives the behavior to be the scale ranged from "Not a problem" to "Large problem". For the "Parental Concern about Child's Diet" construct 
the scale ranged from "Not at all concerned" to "Extremely concerned". And for the "Spousal Stress Related to Child's Mealtime Behaviors" and "Influence of Child's Food Preferences" constructs, participants selected an answer ranging from "Strongly Disagree" to "Strongly Agree".

Reliability and validity were evaluated using two demographically different study samples: CHAMPS and the Ohio study. CHAMPS included mostly well-educated, married and white parents with almost half of the children having autism spectrum disorders, whereas the majority of the Ohio study participants were non-Hispanic black, had less formal education, fewer were married and child developmental disability status was not assessed. ${ }^{12,71}$

Internal Consistency was assessed by calculating Cronbach's correlation coefficient $\alpha$ to assess the correlation of each item with the total score of the domain. For the "Structure of Family Meals" domain, five items were deleted because they were poorly correlated with the scale. After these items were removed, $\alpha$ was .66 in CHAMPS and .73 in the Ohio study. For the "Problematic Child Mealtime Behaviors" domain, $\alpha$ was .93 in CHAMPS and .91 in the Ohio study. For "Parental Concern about Child Diet," $\alpha$ was .90 in CHAMPS and .93 in the Ohio study. For "Use of Food as a Reward," $\alpha$ was .81 in CHAMPS and .76 in the Ohio study. For "Spousal Stress Related to Child's Mealtime Behavior" domain, $\alpha$ was .87 in CHAMPS and .73 in the Ohio study. Because participants must have more than one child and a spouse/partner to complete the "Influence of Child's Food Preferences", Cronbach's $\alpha$ for this section was calculated 
using a much smaller sample. Cronbach's $\alpha$ for this domain .65 in CHAMPS, but was low in the Ohio study at.39.

After an interval of between 10 and 30 days (median $=19.5$ days), test-retest reliabilities were assessed by having 44 parents from CHAMPS repeated Meals in Our Household. There was a high correlation between the domain scores from the first and second administrations. Spearman correlations ranging from $r=0.80$ to $r=0.95$ and averaging $r=0.88$. Test-retest reliabilities were similar for parents of typically developing children and parents of children with autism spectrum disorders.

The questionnaire showed high construct validity by the observed correlations among the domains across in the CHAMPS and Ohio studies. High scores on the "Structure of Family Meals" domain were negatively correlated with the other domains with Spearman correlation coefficients ranging from $r=-0.19$ to $r=-0.52$ in CHAMPS and $r=-0.12$ to $r=-0.51$ in the Ohio study. Positive correlation coefficients were observed among the other five domains in each study ranging from $r=0.24$ to $r=0.67$.

For the purpose of this study the "Problematic Child Mealtime Behaviors" section was divided into two separate constructs: "Occurrence of Problematic Mealtime Behaviors" which contained the questions regarding behavior occurrence and "Parent Concern about Mealtime Behaviors" which contained the questions regarding how much of a problem that behavior is for the parent. Additionally, adaptations were made with the addition of six questions. These six questions were added to the original questions of the corresponding construct and were given the same Likert scale as the other questions 
within the construct. Four questions were added to the "Problematic Child Mealtime Behaviors" construct:

- "My child refuses to try new foods."

- "How much of a problem is it for you that your child refuses to try new foods?"

- "My child is picky about the food he/she will eat."

- "How much of a problem is it for you that your child is picky about the food he/she will eat?"

Additionally, two questions were added to the "Parental Concern about Child's Diet" construct:

- "I am concerned that my child is a picky eater"

- "I am concerned that my child does not eat a variety of foods".

To assess the reliability of the adapted questionnaire used in this study, This study also included a modified food frequency questionnaire to assess diet variety. The FFQ used was modified from the Harvard Service Food Frequency Questionnaire (HSFFQ) for children. The HSFFQ is a four page self and provider administered food frequency questionnaire that was originally validated for use in both pregnant and non-pregnant women. ${ }^{79-82}$ Blum, et al. (1999) validated this instrument for use in children as The Child HSFFQ. ${ }^{74}$ Our modified FFQ was five pages, contained 114 foods items and did not include any additional questions. Parents were asked to mark how often their child consumed each food over the past week. Consuming a variety of foods has been continually recommended to promote overall health and meet nutrient 
needs. ${ }^{83,84}$ Because picky eaters are commonly reported by mothers to consume a limited number and variety of foods, this study focused on the number of different foods consumed over the course of the week within the five major food groups: dairy, protein, grains, fruits, and vegetable (a total of 77 different foods). Therefore the beverages, snack foods/desserts, and miscellaneous food categories were not included in data analysis. Food frequencies were assessed and the foods reported to be consumed at least once weekly were counted to get a total number of foods consumed.

\section{Data Collection}

Prior to initiation of the study, this research was submitted and approved by an Institutional Review Board (IRB) at the Office of Sponsored Programs Office of Research at The Ohio State University. The IRB reviewed the research proposal to minimize risks and ensure the safety of study participants. Because this study includes only questionnaires, there were no anticipated risks to participants.

The researcher was given permission from the child care program director to conduct this study at their site. The researcher met with all preschool classroom teachers individually to explain the study objectives and methods and discuss their role in the data collection process. All parents of preschool children ages 3-5 were eligible to participate and were identified by the child care program. A research packet including a cover letter, demographic questionnaire, the MOHQ, FFQ and an envelope for return, was placed in the parent mailbox of each child within the target age group. Parents were asked by classroom teachers to take the research packets home with them. The cover letter attached to the front of the research packet outlined the purpose and methods of 
the study. It also clearly stated that participation was voluntary and return of completed research materials would signify willingness to participate in the study. (See Appendix) All eligible parents were given 3 weeks to return completed research packet. All potential study participants received a reminder of the study via an email sent by the child care program administration and through the preschool classroom monthly newsletters. A manila envelope was provided to each classroom teacher for completed research packets to be placed. Completed questionnaires were placed in the sealed envelope provided to participants and then returned to the classroom teachers who placed them in the collection envelope. The collection envelopes were each placed in a safe location within each classroom that was designated by the classroom teacher. The researcher returned to every preschool classroom each day to retrieve completed packets from teachers.

Participants who returned their research packet were eligible to participate in a drawing for a \$25.00 Target gift card. The cover letter included directions for participants and a space at the bottom to provide their name and contact information if desired. No identifying information was included anywhere else throughout the research packet. Immediately upon collection by the researcher, the bottom portion of the sheet was removed and entered into the raffle to ensure anonymity of data. At the conclusion of the three week data collection period, four names were drawn by the researcher in the presence of the child care center staff. Raffle winners were notified by the researcher and received their gift card from the child care center administration. Participant 
information was not used for any purpose other than the raffle and was destroyed once the raffle was completed.

There were no anticipated risks to study participants. No personal health information was collected and all obtained data are summarized in aggregate format. During the data collection process all collected research packets were locked in a filing cabinet where only the primary investigator had access.

\section{Assumptions}

For the purpose of this study it was assumed that participants had no prior exposure to the Meals in Our Household Questionnaire. It was also assumed that participant responses were for meals consumed outside of the child care setting.

\section{Statistical Analysis}

Statistical analyses were conducted using IBM SPSS Statistics 21.0. Demographic characteristics of participants were tabulated. The questions within each of the seven child mealtime constructs were added to get a total score for each of these five constructs. For each of the mealtime constructs, only those respondents who answered all of the questions within the construct were included in data analysis. The distribution of scores for each variable was calculated and the median, interquartile range (IQR) minimum and maximum were reported for each. To determine the most frequently occurring problematic behaviors, the five option Likert scale was compressed to include three categories of occurrence: "often/very often", "sometimes", and "rarely/never". The frequency of occurrence for each behavior was then assessed based on this scale. Cronbach's $\alpha$ was calculated for each child mealtime construct to assess the reliability of 
the adapted questionnaire used in this study. For the "Structure of Family Meals" construct, the questions that were found to be poorly correlated with the scale in the previous study were not included in the final analysis. For the "Structure of Family Meals" construct, the questions that were found to be poorly correlated with the scale in the previous study were not included in the final analysis.

The food frequency questionnaire was analyzed by performing a count of the number of different foods consumed within the five major food groups: dairy, protein, grains, fruits, and vegetable (a total of 77 different foods). Respondents without a response for $5 \%$ or greater of the 77 possible foods ( 4 or more missing responses) were considered to have incomplete data and were not included in analysis. The total number of foods was tabulated and the mean, maximum and minimum were reported. Differences between demographic characteristics and total number of foods consumed were assessed using an independent samples t-test and ANOVA where appropriate. The relationship between each of the seven MOHQ variables and the total number of foods consumed, as well as the relationship between particular questions related to picky eating were assessed using Spearman correlation coefficients. A p-value of $<0.05$ was required to determine statistical significance.

\section{Summary}

This study surveyed parents of preschool age children who are attending a large Midwestern University child care program. A descriptive survey design was used to assess the most common types of problematic child mealtime behaviors as reported by 
parents as well as parent concern regarding diet and was compared to the child's individual food frequencies to assess parent perceptions of picky eating. 


\section{Chapter 4: Results and Discussion}

\section{Demographics of Study Participants}

A total of 62 eligible parents completed and returned the research packets for a response rate of 37\%. Demographic data for parents is presented in Table 1 and for children in Table 2. The majority of parent respondents were married, white females with a bachelor's degree or higher. The demographic characteristics of the respondents' children included 36 male and 26 female children. There was an even distribution of children ages three and four, but only six children (10\%) of the sample were age five. A large portion of the children were white and had one or two siblings. Birth order was not included for analysis because multiple respondents who reported their child to have no siblings still answered this question. Only two children (3\%) were reported to have been diagnosed with a developmental disability and were included as part of the general sample. 


\begin{tabular}{|c|c|c|c|}
\hline & $N=62$ & $n$ & $\%$ \\
\hline \multirow[t]{2}{*}{ Gender } & male & 4 & 6 \\
\hline & female & 58 & 94 \\
\hline \multirow[t]{6}{*}{ Ethnicity } & white & 44 & 71 \\
\hline & hispanic or latino & 2 & 3 \\
\hline & black or african american & 4 & 6 \\
\hline & asian/pacific islander & 9 & 15 \\
\hline & other & 1 & 2 \\
\hline & missing data & 2 & 3 \\
\hline \multirow[t]{5}{*}{ Marital Status } & single & 2 & 3 \\
\hline & never married & 2 & 3 \\
\hline & married or domestic partnership & 52 & 84 \\
\hline & divorced & 4 & 7 \\
\hline & separated & 2 & 3 \\
\hline Highest Level of Education & high school or equivalent & 0 & 0 \\
\hline \multirow[t]{7}{*}{ Completed } & vocational/technical school ( 2 yrs) & 1 & 2 \\
\hline & some college & 1 & 2 \\
\hline & bachelor's degree & 18 & 29 \\
\hline & master's degree & 24 & 39 \\
\hline & doctoral degree & 11 & 18 \\
\hline & professional degree & 5 & 8 \\
\hline & other & 2 & 3 \\
\hline Highest Level of Education & high school or equivalent & 3 & 5 \\
\hline \multirow[t]{8}{*}{ Completed by Spouse } & vocational/technical school (2 yrs) & 1 & 2 \\
\hline & some college & 3 & 5 \\
\hline & bachelor's degree & 14 & 23 \\
\hline & master's degree & 15 & 24 \\
\hline & doctoral degree & 9 & 15 \\
\hline & professional degree & 8 & 13 \\
\hline & other & 0 & 0 \\
\hline & missing data & 9 & 15 \\
\hline
\end{tabular}

Table 1. Parent Demographics 


\begin{tabular}{|c|c|c|c|}
\hline & $N=62$ & $\mathrm{n}$ & $\%$ \\
\hline \multirow[t]{2}{*}{ Gender } & male & 36 & 58 \\
\hline & female & 26 & 42 \\
\hline \multirow[t]{3}{*}{ Age } & 3 years & 28 & 45 \\
\hline & 4 years & 28 & 45 \\
\hline & 5 years & 6 & 10 \\
\hline \multirow[t]{6}{*}{ Ethnicity } & white & 37 & 60 \\
\hline & hispanic or latino & 3 & 5 \\
\hline & black or african american & 4 & 6 \\
\hline & asian/pacific islander & 9 & 14 \\
\hline & other & 4 & 7 \\
\hline & missing data & 5 & 8 \\
\hline \multirow[t]{4}{*}{ Number of Siblings } & none, only child & 19 & 31 \\
\hline & one or two & 41 & 66 \\
\hline & three or four & 1 & 2 \\
\hline & more than four & 1 & 2 \\
\hline \multirow[t]{4}{*}{ Birth Order } & youngest child & 11 & 18 \\
\hline & middle child & 2 & 3 \\
\hline & oldest child & 35 & 56 \\
\hline & missing data & 14 & 23 \\
\hline Diagnosed With Developmental & no & 59 & 95 \\
\hline \multirow[t]{2}{*}{ Disability } & yes & 2 & 3 \\
\hline & missing data & 1 & 2 \\
\hline
\end{tabular}

Table 2. Child Demographics

\section{Child Mealtime Constructs}

To assess the reliability of the adapted questionnaire used in this study, Cronbach's $\alpha$ was calculated for each construct. Values were found to be similar to those calculated in the original study. For the "Structure of Family Meals" Cronbach's $\alpha$ was $.692(n=59)$. For the "Occurrence of Problematic Mealtime Behaviors" $\alpha$ was $.808(n=58)$ and for "Parent Concern about Mealtime Behaviors" $\alpha$ was .902 (n=56). For "Parental Concern about Child's Diet" $\alpha$ was .963 (n=61). For the "Use of Food as a 
Reward", Cronbach's $\alpha$ was .742 (n=61) and for "Spousal Stress Related to Child's

Mealtime Behavior" Cronbach's $\alpha$ was $.751(\mathrm{n}=56)$. The lowest value was for the "Influence of "Child's Food Preferences" construct with Cronbach's $\alpha .449$ (n=38). This could likely be attributed to the fact that participants who had only one child or did not report having a spouse/partner were not eligible to answer these questions and this construct was calculated for much fewer participants.

The respondent scores for each of the seven child mealtime constructs were assessed and the median, interquartile range (IQR), minimum and maximum are reported in Table 3.

\begin{tabular}{|c|c|c|c|c|c|c|}
\hline \multicolumn{7}{|c|}{ Descriptive Statistics } \\
\hline & Possible Score Range & $\mathrm{N}$ & Median & IQR & Max. & Min. \\
\hline Structure of Family Meals & $\begin{array}{c}10=\text { never have family style meals } \\
50=\text { always } / \text { almost always have family } \\
\text { style meals }\end{array}$ & 59 & 41.0 & 6.0 & 50.0 & 26.0 \\
\hline $\begin{array}{l}\text { Occurrence of Problematic } \\
\text { Mealtime Behaviors }\end{array}$ & $\begin{array}{c}12=\text { No behaviors occurring } \\
60=\text { all possible behaviors } \\
\text { occurring very often }\end{array}$ & 58 & 31.5 & 8.3 & 49.0 & 18.0 \\
\hline $\begin{array}{l}\text { Parent Concern about } \\
\text { Mealtime Behaviors }\end{array}$ & $\begin{array}{c}12=\text { no behaviors reported } \\
\text { to be a problem } \\
48=\text { all possible behaviors reported to } \\
\text { be a large problem }\end{array}$ & 56 & 22.5 & 14.5 & 43.0 & 12.0 \\
\hline Use of Food as Reward & $\begin{array}{l}5=\text { never use food as a reward } \\
25=\text { always use food as reward }\end{array}$ & 61 & 13.0 & 5.0 & 23.0 & 6.0 \\
\hline $\begin{array}{l}\text { Parent Concern about } \\
\text { Child's Diet }\end{array}$ & $\begin{array}{c}19=\text { not at all concerned } \\
\text { about child's diet } \\
114=\text { extremely concerned } \\
\text { about child's diet }\end{array}$ & 61 & 27.0 & 17.0 & 104.0 & 19.0 \\
\hline $\begin{array}{l}\text { Spousal Stress Related to } \\
\text { Child's Mealtime Behaviors }\end{array}$ & $\begin{array}{c}4=\text { strongly disagree } \\
20=\text { strongly agree }\end{array}$ & 56 & 8.0 & 5.0 & 16.0 & 4.0 \\
\hline $\begin{array}{l}\text { Influence of Child's Food } \\
\text { Preferences on What Other } \\
\text { Family Members Eat }\end{array}$ & $\begin{array}{l}3=\text { strongly disagree } \\
15=\text { strongly agree }\end{array}$ & 38 & 6.0 & 4.0 & 10.0 & 3.0 \\
\hline
\end{tabular}

Table 3. Descriptive Statistics of Mealtime Construct Scores 


\section{Occurrence of Problematic Mealtime Behaviors}

The first research question for this study was to determine what were the most frequent problematic child mealtime behaviors reported by parents. This was assessed by parent responses to the questions in the "Occurrence of Problematic Behaviors" construct. The distribution of responses to the 12 problematic mealtime behaviors that were included in the MOHQ is displayed in Figure 1. To determine which behaviors were reported to occur most often, the number of respondents that selected often or very often for each behavior were counted. The distribution of data is displayed in Figure 2. The behaviors that were reported most frequently as occurring often or very often were "my child refuses to try new foods" by 19 participants (31\%), "my child squirms or fidgets while eating" by 19 participants (31\%), and "my child is picky about the food he or she will eat" by 23 participants (37\%). Behaviors that were reported the least included "my child has tantrums or acts out during meals" by 2 participants (3\%), and "my child refuses to come when it is time to eat" by 3 participants (5\%).

Two of the three problematic mealtime behaviors reported to be occurring most frequently were the two questions that were added regarding picky eating. Of the 23 parents that reported their child was often/very often picky about the foods they will eat, 13 were three years old, 8 were four years old and 2 were five years old. Also, of the 19 respondents that reported their child refuses to try new foods often/very often, 12 were age three, 5 were age four and 2 were age five. Although there were less participants with children age five, there was an equal number with children ages three and four. 


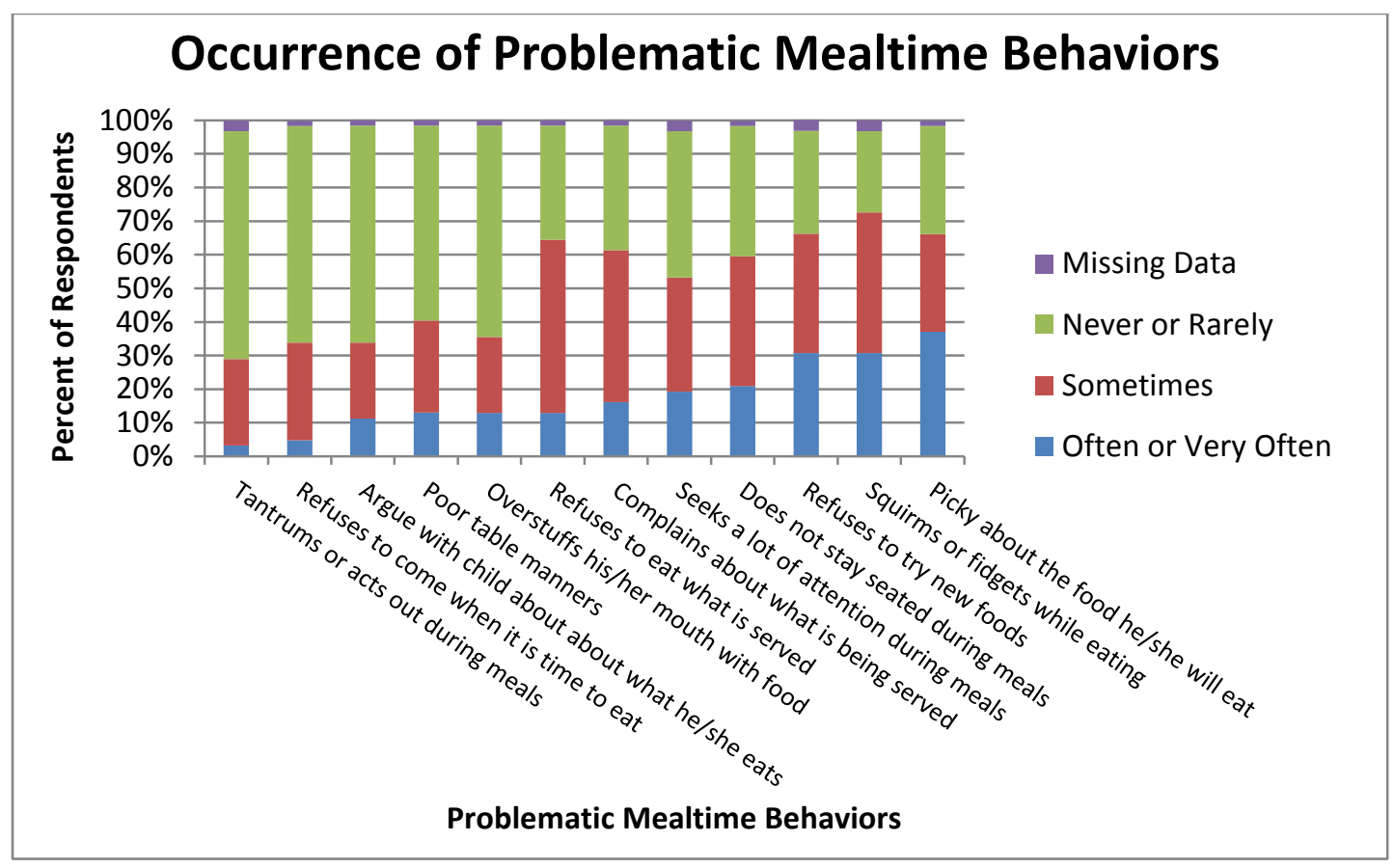

Figure 1. Occurrence of Problematic Mealtime Behaviors 


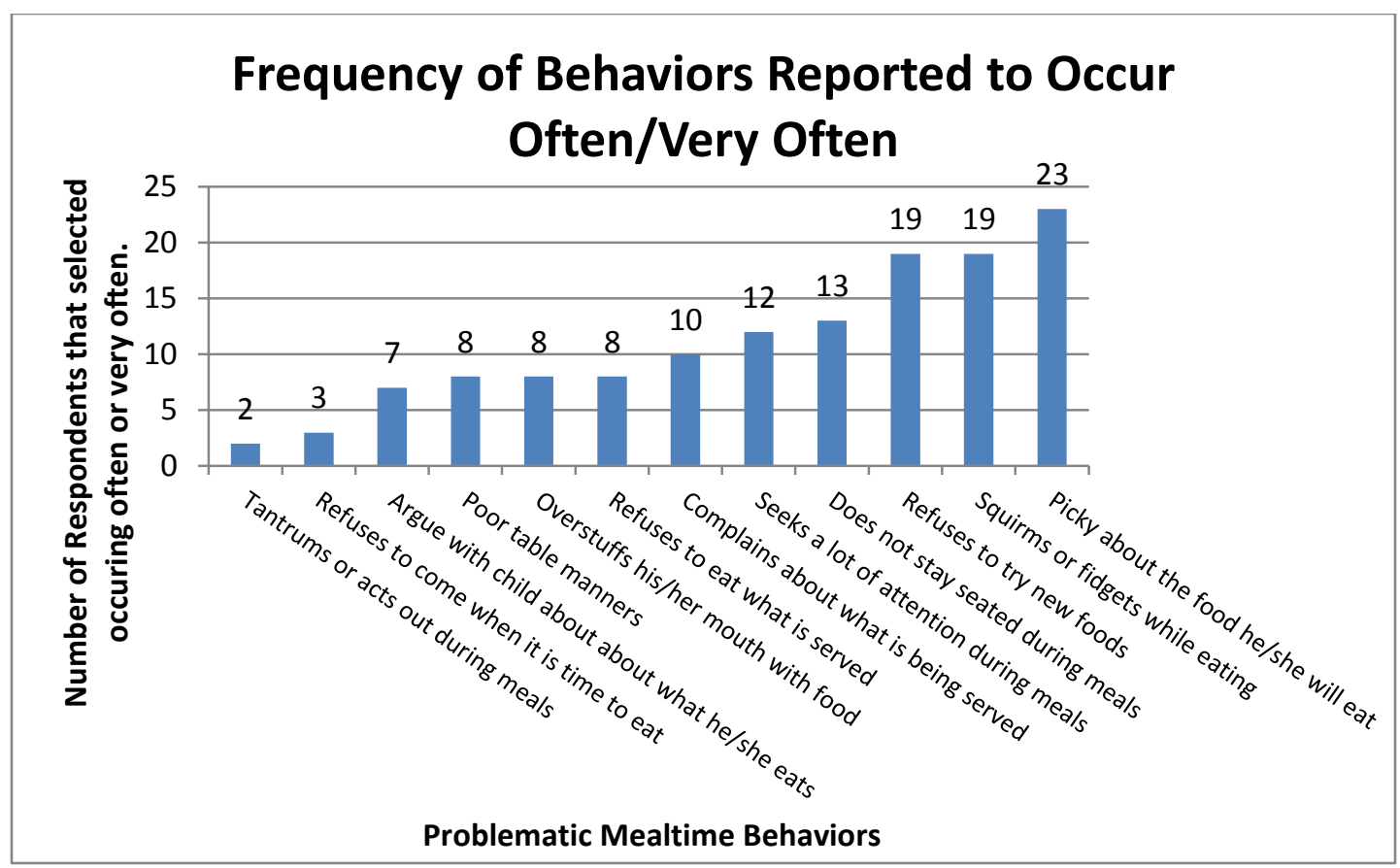

Figure 2. Frequency of Behaviors Reported to Occur Often/Very Often

\section{Variety of Foods Consumed}

To assess the variety of foods consumed, FFQ's were assessed and all foods that were reported to be consumed at least once per week were counted to develop a total number of foods consumed for each respondent. Only foods within the five major food groups (dairy, protein, grains, fruits, vegetables) were included for analysis, providing a total of 77 possible foods consumed. Only respondents who selected a response for $95 \%$ or greater of the 77 possible foods were included in the analysis $(n=59)$.

Overall, the mean number of foods consumed weekly was $38.9 \pm 11.7$ with a minimum of 22 foods consumed and a maximum of 71 foods consumed. The distribution of data is displayed in Figure 3 with regards to the child's gender and age. Females 
consumed on average four more foods per week then males, but this difference was not statistically significant. Three and four year olds consumed a similar number of foods per week, whereas children age five consumed on average 11 more foods. Although there was an observable increase in the total number of foods consumed from age four to five, the difference between the three groups was not statistically significant.

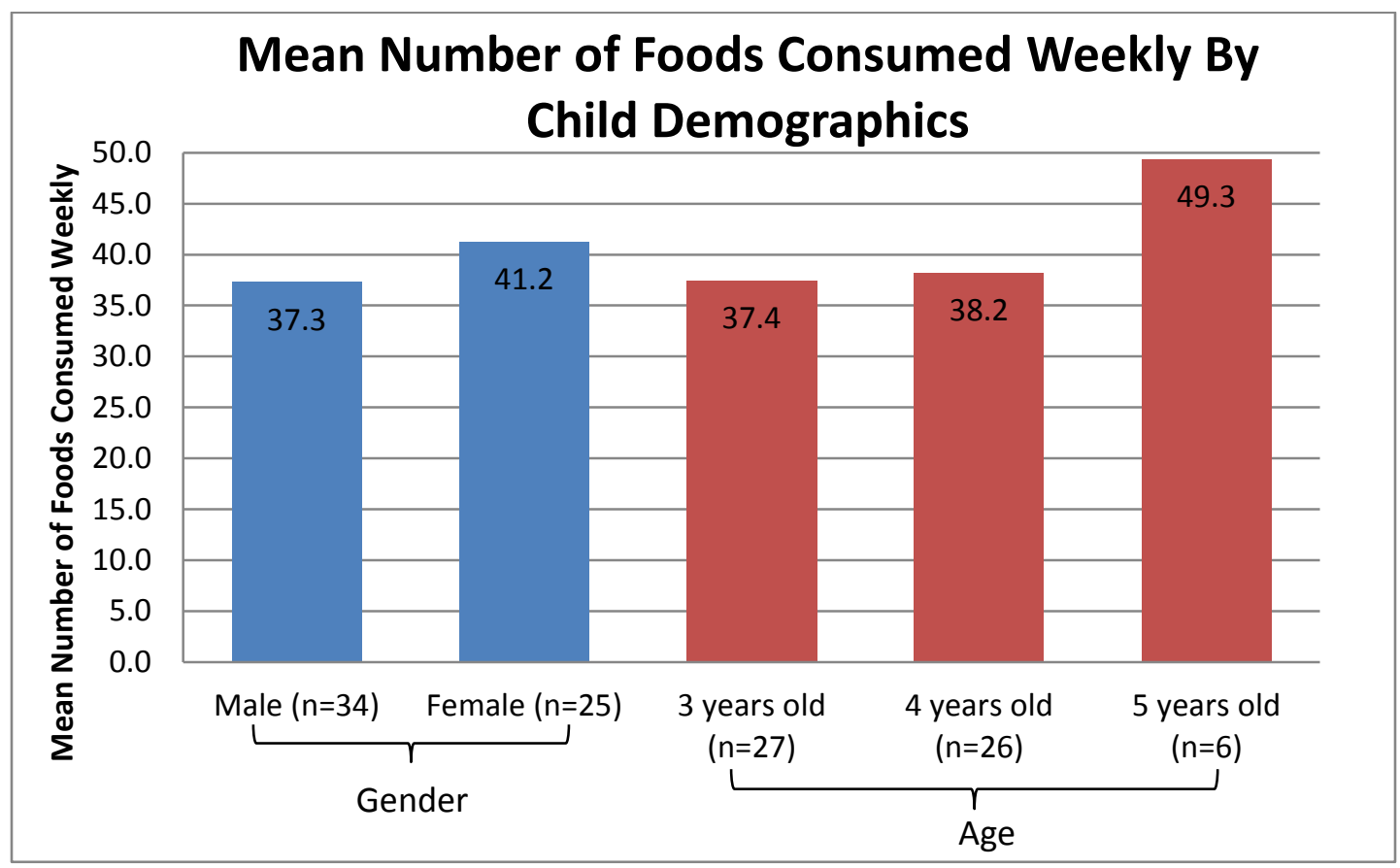

Figure 3. Mean Number of Foods Consumed Weekly by Child Demographics 


\section{Relationships between Parent Concern and Diet Variety}

To assess the relationship between the child mealtime constructs and the number of foods consumed, correlation was assessed using Spearman correlation coefficients. Spearman correlation coefficients and p-values for each are reported in Table 4.

The second research question assessed the relationship between parental concern about their child's diet and the variety of foods consumed by the child as measured by the FFQ. This relationship was assessed by a Spearman Correlation between the total score for the "Parent Concern about Child's Diet" construct and the total number of foods consumed. The median respondent score for "Parent Concern about Child's Diet" was 27, which is consistent with "little to no concern". There was a wide distribution of scores ranging from a minimum of 19 (almost no concern) to a maximum of 104 (extremely high level of concern). Of the 62 total respondents, 59 had complete data for both the "Parental Concern about Child's Diet" construct and the FFQ and were included in the correlation analysis. Overall, "Parent Concern about Child's Diet" was not correlated with the total number of foods consumed by the child $(\mathrm{r}=.005, \mathrm{p}=.968)$.

Our third research question assessed the relationship between parental concern about their child's mealtime behaviors and the variety of foods consumed by the child as assessed by the FFQ. This relationship was assessed by a Spearman Correlation between the total score for the "Parent Concern about Mealtime Behaviors" construct and the total number of foods the child consumed. The mean respondent score for the "Parent Concern about Mealtime Behavior" construct was 31.5 (small to medium level of concern). There was a wide distribution of scores ranging from a minimum of 12 (no concern) to a 
maximum of 43 (very high level of concern). Of the 62 total respondents, 53 had complete data for both the "Parent Concern about Mealtime Behaviors" construct and the FFQ and were included in the correlation analysis. Overall, "Parental Concern about Child's Mealtime Behavior" was not correlated with the total number of foods consumed by the child $(\mathrm{r}=.084, \mathrm{p}=.550)$. (Table 4$)$

\begin{tabular}{|c|c|c|c|c|c|c|c|}
\hline \multicolumn{8}{|c|}{$\begin{array}{c}\text { Correlational Analysis of Weekly Number of Foods Consumed and Child } \\
\text { Mealtime Constructs Using Spearman Correlation Coefficients }\end{array}$} \\
\hline & $\begin{array}{l}\text { Weekly } \\
\text { Number } \\
\text { of Foods } \\
\text { Consumed }\end{array}$ & $\begin{array}{l}\text { Child's } \\
\text { Influence }\end{array}$ & $\begin{array}{l}\text { Spousal } \\
\text { Stress }^{a}\end{array}$ & $\begin{array}{l}\text { Parent } \\
\text { Concern } \\
\text { about } \\
\text { Child's } \\
\text { Diet } \\
\end{array}$ & $\begin{array}{c}\text { Use of } \\
\text { Food as } \\
\text { a } \\
\text { Reward }\end{array}$ & $\begin{array}{l}\text { Parent } \\
\text { Concern } \\
\text { about } \\
\text { Behaviors }\end{array}$ & $\begin{array}{l}\text { Occurrence } \\
\text { of Problem } \\
\text { Behaviors }\end{array}$ \\
\hline Structure of Family Meals & $.356^{* *}$ & -.081 & -.231 & -.252 & .118 & .030 & -.205 \\
\hline $\begin{array}{l}\text { Occurrence of Problem } \\
\text { Behaviors }\end{array}$ & .011 & .264 & $.522^{* *}$ & $.509^{* *}$ & .160 & $.683^{* *}$ & \\
\hline $\begin{array}{l}\text { Parent Concern about } \\
\text { Behaviors }\end{array}$ & .084 & .194 & $.387^{* *}$ & $.539^{* *}$ & .248 & & \\
\hline Use of Food as a Reward & .138 & .283 & .063 & .126 & & & \\
\hline $\begin{array}{l}\text { Parent Concern about } \\
\text { Child's Diet }\end{array}$ & .005 & $.375^{*}$ & .254 & & & & \\
\hline Spousal Stress ${ }^{a}$ & $.280^{*}$ & $.325^{*}$ & & & & & \\
\hline Child's Influence $^{\mathrm{b}}$ & $.388^{*}$ & & & & & & \\
\hline \multicolumn{8}{|c|}{$\begin{array}{l}\text { **. Correlation is significant at the } 0.01 \text { level (2-tailed). } \\
\text { *. Correlation is significant at the } 0.05 \text { level (2-tailed). } \\
\text { a Spousal Stress Related to Child's Mealtime Behaviors } \\
\text { b Influence of Child Food Preferences on what other Fam }\end{array}$} \\
\hline
\end{tabular}

Table 4. Correlational Analysis of Weekly Number of Foods Consumed and Child Mealtime Using Spearman Correlation Coefficients 


\section{Relationships between Child Mealtime Constructs}

The relationship between the five additional child mealtime constructs and the total number of foods consumed was also assessed using Spearman correlation coefficients. There was a statistically significant correlation between the total number of foods consumed and the "Structure of Family Meals" $(\mathrm{r}=.356)$. There were statistically significant correlations between the total number of foods consumed with "Spousal Stress Related to Child's Mealtime Behavior" $(\mathrm{r}=.280)$ and "Influence of Child's Food Preferences" $(\mathrm{r}=.388)$.

Additionally, the relationships between the each of the seven child mealtime constructs were assessed. The "Occurrence of Problematic Mealtime Behaviors" construct was shown to be correlated with multiple constructs. There was a statistically significant correlation between the "Occurrence of Problematic Mealtime Behaviors" and "Parent Concern about Mealtime Behaviors" $(\mathrm{r}=.683)$, "Spousal Stress Related to Child's Mealtime Behaviors" $(\mathrm{r}=.522)$ and "Parental Concern about Child's Diet" $(\mathrm{r}=.509)$.

"Parent Concern about Mealtime Behaviors" was also shown to have a statistically significant correlation with "Parental Concern about Child's Diet" $(r=.539)$ and "Spousal Stress Related to Child's Mealtime Behaviors" $(\mathrm{r}=.387)$. The "Influence of Child's Food Preferences" was shown to be correlated with "Parental Concern about Child's Diet" ( $\mathrm{r}=.375)$ and "Spousal Stress Related to Child's Mealtime Behaviors" $(\mathrm{r}=.325)$. Both correlations were statistically significant. 


\section{Parent Perceptions of Picky Eating Behaviors}

To assess parent perceptions of picky eating behaviors the question "my child is a picky eater" and "my child does not eat a variety of foods" were added to the "Parent Concern about Child's Diet" construct. The relationship between "my child is a picky eater" and the other questions related to picky eating within the "Parent Concern about Child's Diet" construct were assessed using Spearman Correlation Coefficients. Higher levels of concern on "my child is a picky eater" were correlated with higher levels of concern "my child does not eat a variety of foods" $(r=.726)$, "my child will not try new foods" $(\mathrm{r}=.650)$, "my child is not flexible about what he/she eats" $(\mathrm{r}=.640)$ and "my child eats only a few types of food $(r=.715)$.

Additionally, the question "my child is a picky about the food he/she will eat" and "my child refuses to try new foods" were added to "Problematic Child Mealtime Behaviors" construct. The relationship between "my child is picky about the food he/she will eat" and the other questions related to picky eating within the "Parent Concern about Mealtime Behaviors" construct were assessed using Spearman Correlation Coefficients. Higher frequency of occurrence on "my child is picky about the food he/she will eat" was correlated with higher frequency on "my child refuses to try new foods" $(\mathrm{r}=.771)$, "my child complains about what is being served" $(\mathrm{r}=.639)$, "I argue with my child about what he/she eats" $(\mathrm{r}=.403)$, and "my child refuses to eat what is served" $(\mathrm{r}=.659)$.

\section{Discussion}

This study found the most frequently reported problematic child mealtime behaviors by parents to be that their child squirms or fidgets while eating, refuses to try 
new foods and is picky about the food he or she will eat. Both the questions regarding food refusal and picky eating were added to the "Parental Concern about Child's Diet" construct. The fact that parents in our sample endorsed both of these behaviors as two of the most frequent suggests that parents may associate the refusal of new foods with picky eating. This is consistent with past research that has found unwillingness to try new foods as one of the common behaviors reported by mothers in regards to picky eating. ${ }^{5,7-10}$

Of the 23 parents that reported their child was often/very often picky about the foods he/she will eat, the majority were age three, a few were age four and even less were age five. The same was true for those respondents that reported their child refuses to try new foods. Additionally, it was found that three and four year olds consumed a similar number of foods per week, whereas children age five consumed on average 11 more foods. Although the difference between the groups was not statistically significant, this data is consistent with past research and suggests that picky eating behaviors in typically developing children may decrease with as age and exposure increase..$^{10,11,21,26}$ Regarding gender, females consumed four more foods on average per week then males, but this was not a significant difference. This is also consistent with past research and suggests that picky eating behaviors is equally prevalent in young males and females. ${ }^{7,11}$

No correlation was found between parental concern about their child's diet and the variety of foods consumed by the child. This suggests that parent concern about what the child is consuming does accurately reflect the quantity and variety of foods the child is consuming. In this sample, there were a few children who were consuming larger numbers of food per week then the sample average whose parents were also exhibiting 
high levels of concern regarding their child's diet. One possible explanation for this is that parents that are more concerned with their child's diet may intervene more in an attempt to get their child to consume more foods. Other studies have found that parents who perceive their child to be picky eaters are more likely to pressure their child to eat or use alternative methods such as offering food as a reward, preparing separate meals for the child or allowing distractions during meals..$^{7-9,44,49}$

In contrast, there were also a few children who were consuming a much fewer number of foods per week then the sample average whose parents expressed very little concern regarding their child's diet. There are many potential reasons that parents may not be concerned about their child's diet. Some possible explanations may be a lack of knowledge regarding age appropriate diet recommendations, an assumption that the child is just being difficult or that the parent has a lack of variety in their own diet resulting in limited food choices for the child.

Higher levels of "Parent Concern about Mealtime Behavior" were positively correlated with "Occurrence of Problematic Mealtime Behaviors" which implies that parent level of concern is appropriately elevated with an increased occurrence of problematic behaviors. However, there was no significant correlation between "Parental Concern about Mealtime Behaviors" and the total number of foods consumed by the child. This suggests that parent concern about mealtime behaviors does not accurately represent the child's diet variety. Similarly, we found no correlation between "Occurrence of Problematic Mealtime Behaviors" and the total number of foods consumed which suggests that the occurrence of problematic mealtime behaviors is not 
affecting the variety of foods the child is consuming. A few of the children whose parents reported a high level of concern regarding their behavior were still consuming well above the average number of foods per week for our sample and a few who reported low levels of concern were consuming well below the average. Despite this lack of correlation between mealtime behaviors and the total number of foods consumed, it is important to consider that a high occurrence of problematic mealtime behaviors can cause greater parent frustration which could result in negative effects on the child's future intake and food preferences. ${ }^{44,49,50}$

There did however appear to be correlations between other child mealtime behavior constructs and the number of weekly foods consumed including "Structure of Family Meals", "Spousal Stress Related to Child's Mealtime Behaviors", and the "Influence of Child's Food Preferences". The correlation between the total number of foods consumed and the "Structure of Family Meals" is consistent with other research linking regular family meals with beneficial health and nutrition outcomes in children and adolescents. ${ }^{31,85-89}$ More specifically, the construct regarding family mealtimes assessed the specific structure of family mealtimes. The parents that reported having family meals closely aligned to traditional family-style meals (ex. sitting at the table with family, without television, eating home-cooked meals, etc.) were consuming a greater total number of foods. Correlations with the "Influence of Child's Food Preferences" construct should be interpreted cautiously because only those with both a spouse and multiple children were included so the sample size was much smaller $(n=38)$. 
High levels of "Spousal Stress Related to Child's Mealtime Behaviors" were shown to be positively correlated with multiple other mealtime behavior constructs including "Occurrence of Problematic Mealtime Behaviors", "Parent Concern about Mealtime Behaviors" and "Influence of Child's Food Preferences". It is important to consider that the level of spousal stress related to the child's mealtime behaviors is a representation of how the parent respondent believes their child's behaviors are affecting their spouse and is likely perceived as being similar to their own level of stress and concern.

"Parent concern about child's diet was positively correlated with both "Occurrence of Problematic Mealtime Behaviors" and "Parent Concern about Mealtime Behaviors". This implies that parent concerns regarding diet and behaviors are similar and one may possibly influence the other. Parents have commonly reported picky eating behaviors to be a consumption of a limited number and variety of foods, unwillingness to try new foods, strong food preferences and dislikes, requiring specific food preparation and presentation, and having longer lasting mealtimes. ${ }^{5,7-10}$ In this study, this stood true in that parents who felt that their child is a picky eater were also concerned that their child does not eat a variety of foods, will not try new foods, complains about what is served, is not flexible about what he/she eats, and eats only a few types of food.

This study has important implications on nutrition assessment in children. Health professionals typically must rely on parent report to assess a child's eating behaviors and diet quality. If there are no obvious signs of malnutrition, clinicians will simply ask parents whether or not they have any nutrition concerns about their child and none are 
present, they generally do not proceed with nutrition assessment. Often, parents will say that their child is a "picky eater" and receive a response that they will just "grow out of it". Although this is true for most children, some children may have a more serious feeding problem and the lack of a clear definition of "picky eating" makes this difficult to assess without additional questioning. This study has also demonstrated that the level of parent concern regarding their child's mealtime behaviors and diet may not be a good measure of how the child is actually eating. Thus, it is important that clinicians do not simply rely on broad overall nutrition questions to assess the child's eating habits. Although children whose parents express high levels of concern about their child's eating habit are typically referred to a Registered Dietitian for assessment, there appears to be little nutrition assessment conducted with parents who express little concern. More specific questioning regarding mealtime behaviors, as well as gathering an overall picture of the child's diet through a food frequency questionnaire or 3-day food record, may be necessary to determine the actual severity of the child's behaviors and diet variety.

\section{Limitations}

This study was limited to parents of preschool children ages 3-5 and is not generalizable to children in other age groups (ex. infants, toddlers). In addition, this study was conducted using a convenience sample at a university child care program which is not representative of all preschool programs. The majority of parent respondents were married, white females with a bachelor's degree or higher so the results of this study are likely not representative of male parents or those with lower education levels. A further limitation of the study is that The Meals in Our Household Questionnaire is subject to 
social desirability bias and participants may differ in their levels of understanding and interpreting the questionnaires. The FFQ is also subject to bias in that participants may overestimate foods they believe to be healthy. Because this study was not concerned with portion sizes overestimation should have little effect on the results. In addition, the FFQ only assessed diet variety over a one week period which could be dependent on the foods the child was offered that particular week and may not be representative of all the foods that the child consumes and. Also, the foods listed on the FFQ may not be reflective of the dietary patterns of all participants and ethnic differences in food selection may not be captured.

\section{Future Research}

Additional research is needed to better assess the reliability of parent perceptions of their child's eating behaviors and diet variety. Future research should include a more demographically diverse sample. A multi-site study with participants from more than one preschool or day care center may be helpful in increasing sample size and demographic diversity. There is also a need for research in clinical settings to determine how health professionals typically respond to parent concerns about their child's eating habits and diet. Because various interpretations of picky eating continue to exist, standardized methods for questions regarding eating behaviors and diet should be developed to help clinicians better assess the child's nutrition status. 


\title{
Chapter 5: The Relationship between Parent Perceptions of Preschooler Mealtime Behaviors and Diet Variety
}

\begin{abstract}
Objective: To assess the most common parent concerns about their preschooler's eating habits and determine how individual child food frequencies correlate with parent perceptions of the child's diet and mealtime behaviors.

Design: Descriptive study using a parent-report mealtime behavior questionnaire and an adapted food frequency questionnaire.

Setting: A large Midwestern University child care program

Participants: 62 parents of children ages 3-5

Variables Measured: Most frequently occurring problematic child mealtime behaviors, parent concern about child mealtime behaviors, parent concern about child's diet, child's diet variety
\end{abstract}

Analysis: Independent samples t-test, ANOVA, Spearman correlation. P-value $<0.05$ was required to determine statistical significance.

Results: The most frequent problematic child mealtime behaviors reported by parents were that their child squirms or fidgets while eating (31\%), refuses to try new foods (31\%) and is picky about the food he or she will eat (37\%). No significant correlation 
was found between the total number of foods consumed and parental concern about mealtime behaviors $(r=.084)$ or parent concern about diet $(r=.005)$.

Conclusions and Implications: Parent concerns about their child's diet and mealtime behaviors may not be appropriate measures of the child's diet. Clinicians should not rely on broad nutrition questions to assess child mealtime behaviors and diet, but should perform more specific questioning and use additional assessment methods.

\section{INTRODUCTION}

Food selectivity or "picky eating" is common in young children and can create a stressful environment at family mealtimes. Between $25-35 \%$ of children in the United States are considered picky eaters and that statistic increases in those with chronic medical conditions. ${ }^{1}$ Picky eating most commonly occurs during early childhood when food preferences and eating habits are being established. ${ }^{2-4}$ It is during this time period that food preferences are shaped which may impact eating habits for the rest of the child's life.

Previous research has attempted to define picky eating using various definitions, but the wide variety and complexity of feeding problems in children has caused discrepancies in the subsequent definitions and classifications. ${ }^{7,10-15}$ Past definitions have typically focused on either limited variety of food choices or a limited volume of food consumed. Current research has used these definitions and incorporates numerous other characteristics to describe picky eating. ${ }^{5,6}$ Parent report is one of the most common 
methods used to assess eating behaviors in early childhood and therefore, picky eating descriptions typically rely on this as the method for data collection. The most common behaviors reported by mothers in regards to picky eating include consumption of a limited number and variety of foods, unwillingness to try new foods, strong food preferences and dislikes, requiring specific food preparation and presentation, and having long lasting mealtimes. ${ }^{5,7-10}$

Most children will exhibit some form of picky eating during early childhood as a normal component of child development. This is often expressed as the desire to exert their growing independence at mealtimes. Many children will "grow out" of this stage, but some children's picky eating habits can persist and if not treated can put them at risk for both short and long term health consequences. ${ }^{16-18}$ In order to limit the health risks, steps to improve the child's eating habits and feeding environment should begin as soon as possible. Unfortunately, standardized diagnostic and treatment methods do not exist which may impact the ability to treat.

The lack of a standard definition of "picky eating" has made it difficult for parents, teachers and clinicians to effectively communicate about children's feeding problem. This can lead to discrepancies in diagnosis and treatment among health professionals in this field. Because there are no standardized criteria, health professionals must often rely on parent report to assess child eating habits and behaviors. The purpose of this study was to further examine the description of picky eating by assessing parent perceptions of preschool children's mealtime behaviors and eating habits. Additionally, this study assessed the relationship between parent concerns regarding both mealtime 
behaviors and diet and the child's diet variety to better evaluate the reliability of parent report of their child's diet and eating habits.

\section{METHODS}

Prior to initiation of the study, this research was submitted and approved by an Institutional Review Board (IRB) at the Office of Sponsored Programs Office of Research at The Ohio State University. Additionally, the researcher was given permission from the child care program director to conduct this study at their site.

\section{Sample Population}

All parents of preschool children ages 3-5 who were attending a large Midwestern University child care program were eligible to participate and were identified by the child care program staff. There were 167 children in the target age group enrolled in preschool classrooms at the child care center when the study was conducted.

\section{Study Design}

A research packet including a cover letter outlining the study purpose and methods, demographic questionnaire, Meals in Our Household Questionnaire (MOHQ), a modified food frequency questionnaire (FFQ) and return envelope was distributed to eligible participants. (See Appendix) Participation was entirely voluntary and all eligible parents were given 3 weeks to return completed research packet if desired. Parents who returned their research packet were eligible to participate in a random drawing for one of four gift cards at the end of the data collection period. 


\section{Study Instruments}

The two instruments used in this study are the MOHQ and an adapted FFQ. The MOHQ is a parent-report questionnaire that is used to study family mealtime environments and children's mealtime behaviors. The questionnaire was developed and validated for use in children ages 3-11 years old and measures mealtime across six domains: 1) structure of family meals, 2) problematic child mealtime behaviors, 3) use of food as a reward, 4) parental concern about child diet, 5) spousal stress related to child's mealtime behavior, and 6) influence of child's food preferences on what other family members eat ${ }^{71}$. Each section of the questionnaire contains a separate Likert Scale of responses for study participants to select from.

Reliability and validity were previously evaluated in the study conducted by Anderson, Must, Curtin \& Bandini (2012) using two demographically different study samples: CHAMPS and the Ohio study. ${ }^{71}$ Internal Consistency was assessed by calculating Cronbach's correlation coefficient $\alpha$ to assess the correlation of each item with the total score of the construct. The two Cronbach's $\alpha$ for the "Structure of Family Meals" in the CHAMPS and Ohio studies were .66 and .73, for the "Problematic Child Mealtime Behaviors" were .93 and.91, for "Parental Concern about Child Diet" were .90 and .93, for "Use of Food as a Reward" were .81 and .76 and for "Spousal Stress Related to Child's Mealtime Behavior" were.87 and .73. Because participants must have more than one child and a spouse/partner to complete the "Influence of Child's Food Preferences" construct, Cronbach's $\alpha$ for this section was calculated using a much smaller sample and were .65 and .39 . 
There was a high test-retest reliability with Spearman correlations ranging from $r=0.80$ to $r=0.95$ (average $=0.88$ ). Additionally, the MOHQ showed high construct validity by the observed correlations among the domains across in the CHAMPS and Ohio studies. High scores on the "Structure of Family Meals" domain were negatively correlated with the other domains with Spearman correlation coefficients ranging from $r=-0.19$ to $r=-0.52$ in CHAMPS and $r=-0.12$ to $r=-0.51$ in the Ohio study. Positive correlation coefficients were observed among the other five domains in each study ranging from $r=0.24$ to $r=0.67$.

For the purpose of this study the "Problematic Child Mealtime Behaviors" section was divided into two separate constructs: "Occurrence of Problematic Mealtime Behaviors" which contained the questions regarding behavior occurrence and "Parent Concern about Mealtime Behaviors" which contained the questions regarding how much of a problem that behavior is for the parent. Additionally, six questions were added to the original questions of the corresponding construct and were given the same Likert scale as the other questions within the construct. Four questions were added to the "Problematic Child Mealtime Behaviors" construct:

Four questions were added to the "Problematic Child Mealtime Behaviors" construct:

- "My child refuses to try new foods."

- "How much of a problem is it for you that your child refuses to try new foods?"

- "My child is picky about the food he/she will eat." 
- "How much of a problem is it for you that your child is picky about the food he/she will eat?"

Additionally, two questions were added to the "Parental Concern about Child's Diet" construct:

- "I am concerned that my child is a picky eater"

- "I am concerned that my child does not eat a variety of foods".

This study also included a modified food frequency questionnaire to assess diet variety. The FFQ was adapted from the Harvard Service Food Frequency Questionnaire (HSFFQ) for children. The HSFFQ is a self and provider administered food frequency questionnaire that was originally validated for use in both pregnant and non-pregnant

women, but has since been adapted and validated for use in children as well. ${ }^{74-82}$ Our modified FFQ contained 114 foods items. Because picky eaters are commonly reported by mothers to consume a limited number and variety of foods, this study focused on the number of different foods consumed. Parents were asked to mark how often their child consumed each food over the past week.

\section{Statistical Analysis}

Statistical analyses were conducted using IBM SPSS Statistics 21.0. Demographic characteristics of participants were tabulated. The questions within each of the seven child mealtime constructs were added to get a total score for each construct. For each of the mealtime constructs, only those respondents who answered all of the questions within the construct were included in data analysis. The distribution of scores for each variable was then calculated and the median, interquartile range (IQR) minimum and maximum 
were reported for each. To determine the most frequently occurring problematic behaviors, the five option Likert scale was compressed to include three categories of occurrence: "often/very often", "sometimes", and "rarely/never". Cronbach's $\alpha$ was calculated for each child mealtime construct to assess the reliability of the adapted questionnaire used in this study. For the "Structure of Family Meals" construct, the questions that were found to be poorly correlated with the scale in the previous study were not included in the final analysis.

The food frequency questionnaire was analyzed by performing a count of the number of different foods consumed within the five major food groups: dairy, protein, grains, fruits, and vegetables for a total of 77 possible different foods. Respondents missing responses for $5 \%$ or greater of the 77 possible foods ( $\geq 4$ responses) were considered to have incomplete data and were not included in analysis. The total number of foods was tabulated and the mean, maximum and minimum were reported. Differences between demographic characteristics and total number of foods consumed were assessed using an independent samples t-test and ANOVA where appropriate. The relationship between each of the seven MOHQ variables and the total number of foods consumed, as well as the relationship between particular questions related to picky eating were assessed using Spearman correlation coefficients. A p-value of $<0.05$ was required to determine statistical significance. 


\section{RESULTS}

\section{Demographics of Study Participants}

A total of 62 eligible parents completed and returned the research packets for a response rate of $37 \%$. Demographic data for parents is presented in Table 1 and for children in Table 2 . Because only two children (3\%) were reported to have been diagnosed with a developmental disability they were included as part of the general sample. 


\begin{tabular}{|c|c|c|c|}
\hline & $N=62$ & $\mathrm{n}$ & $\%$ \\
\hline \multirow[t]{2}{*}{ Gender } & male & 4 & 6 \\
\hline & female & 58 & 94 \\
\hline \multirow[t]{6}{*}{ Ethnicity } & white & 44 & 71 \\
\hline & hispanic or latino & 2 & 3 \\
\hline & black or african american & 4 & 6 \\
\hline & asian/pacific islander & 9 & 15 \\
\hline & other & 1 & 2 \\
\hline & missing data & 2 & 3 \\
\hline \multirow[t]{5}{*}{ Marital Status } & single & 2 & 3 \\
\hline & never married & 2 & 3 \\
\hline & married or domestic partnership & 52 & 84 \\
\hline & divorced & 4 & 7 \\
\hline & separated & 2 & 3 \\
\hline \multirow{8}{*}{$\begin{array}{l}\text { Highest Level of Education } \\
\text { Completed }\end{array}$} & high school or equivalent & 0 & 0 \\
\hline & vocational/technical school ( 2 yrs) & 1 & 2 \\
\hline & some college & 1 & 2 \\
\hline & bachelor's degree & 18 & 29 \\
\hline & master's degree & 24 & 39 \\
\hline & doctoral degree & 11 & 18 \\
\hline & professional degree & 5 & 8 \\
\hline & other & 2 & 3 \\
\hline \multirow{9}{*}{$\begin{array}{l}\text { Highest Level of Education } \\
\text { Completed by Spouse }\end{array}$} & high school or equivalent & 3 & 5 \\
\hline & vocational/technical school (2 yrs) & 1 & 2 \\
\hline & some college & 3 & 5 \\
\hline & bachelor's degree & 14 & 23 \\
\hline & master's degree & 15 & 24 \\
\hline & doctoral degree & 9 & 15 \\
\hline & professional degree & 8 & 13 \\
\hline & other & 0 & 0 \\
\hline & missing data & 9 & 15 \\
\hline
\end{tabular}

Table 5. Parent Demographics 


\begin{tabular}{|c|c|c|c|}
\hline & $\mathrm{N}=62$ & $\mathrm{n}$ & $\%$ \\
\hline \multirow[t]{2}{*}{ Gender } & male & 36 & 58 \\
\hline & female & 26 & 42 \\
\hline \multirow[t]{3}{*}{ Age } & 3 years & 28 & 45 \\
\hline & 4 years & 28 & 45 \\
\hline & 5 years & 6 & 10 \\
\hline \multirow[t]{6}{*}{ Ethnicity } & white & 37 & 60 \\
\hline & hispanic or latino & 3 & 5 \\
\hline & black or african american & 4 & 6 \\
\hline & asian/pacific islander & 9 & 14 \\
\hline & other & 4 & 7 \\
\hline & missing data & 5 & 8 \\
\hline \multirow[t]{4}{*}{ Number of Siblings } & none, only child & 19 & 31 \\
\hline & one or two & 41 & 66 \\
\hline & three or four & 1 & 2 \\
\hline & more than four & 1 & 2 \\
\hline \multirow[t]{4}{*}{ Birth Order } & youngest child & 11 & 18 \\
\hline & middle child & 2 & 3 \\
\hline & oldest child & 35 & 56 \\
\hline & missing data & 14 & 23 \\
\hline Diagnosed With Developmental & no & 59 & 95 \\
\hline \multirow[t]{2}{*}{ Disability } & yes & 2 & 3 \\
\hline & missing data & 1 & 2 \\
\hline
\end{tabular}

Table 6. Child Demographics

\section{Child Mealtime Constructs}

To assess the reliability of the adapted questionnaire used in this study, Cronbach's $\alpha$ was calculated for each construct. Values were found to be similar to those calculated in the original study. For the "Structure of Family Meals" Cronbach's $\alpha$ was .692 (n=59). For the "Occurrence of Problematic Mealtime Behaviors" $\alpha$ was $.808(n=58)$ and for "Parent Concern about Mealtime Behaviors" $\alpha$ was .902 (n=56). For "Parental Concern about Child's Diet" $\alpha$ was .963 (n=61). For the "Use of Food as a Reward", Cronbach's $\alpha$ 
was .742 (n=61) and for "Spousal Stress Related to Child's Mealtime Behavior"

Cronbach's $\alpha$ was .751 ( $\mathrm{n}=56)$. The lowest value was for the "Influence of "Child's Food

Preferences" construct with Cronbach's $\alpha .449(\mathrm{n}=38)$. This could likely be attributed to

the fact that participants who had only one child or did not report having a spouse/partner

were not eligible to answer these questions and this construct was calculated for much

fewer participants.

The respondent scores for each of the seven child mealtime constructs were assessed and the descriptive statistics are reported in Table 3.

\begin{tabular}{|c|c|c|c|c|c|c|}
\hline \multicolumn{7}{|c|}{ Descriptive Statistics } \\
\hline & Possible Score Range & $\mathrm{N}$ & Median & IQR & Max. & Min. \\
\hline Structure of Family Meals & $\begin{array}{c}10=\text { never have family style meals } \\
50=\text { always } / \text { almost always have family } \\
\text { style meals }\end{array}$ & 59 & 41.0 & 6.0 & 50.0 & 26.0 \\
\hline $\begin{array}{l}\text { Occurrence of Problematic } \\
\text { Mealtime Behaviors }\end{array}$ & $\begin{array}{c}12=\text { No behaviors occurring } \\
60=\text { all possible behaviors } \\
\text { occurring very often }\end{array}$ & 58 & 31.5 & 8.3 & 49.0 & 18.0 \\
\hline $\begin{array}{l}\text { Parent Concern about } \\
\text { Mealtime Behaviors }\end{array}$ & $\begin{array}{c}12=\text { no behaviors reported } \\
\text { to be a problem } \\
48=\text { all possible behaviors reported to } \\
\text { be a large problem }\end{array}$ & 56 & 22.5 & 14.5 & 43.0 & 12.0 \\
\hline Use of Food as Reward & $\begin{array}{l}5=\text { never use food as a reward } \\
25=\text { always use food as reward }\end{array}$ & 61 & 13.0 & 5.0 & 23.0 & 6.0 \\
\hline $\begin{array}{l}\text { Parent Concern about } \\
\text { Child's Diet }\end{array}$ & $\begin{array}{l}19=\text { not at all concerned } \\
\text { about child's diet } \\
114 \text { = extremely concerned } \\
\text { about child's diet }\end{array}$ & 61 & 27.0 & 17.0 & 104.0 & 19.0 \\
\hline $\begin{array}{l}\text { Spousal Stress Related to } \\
\text { Child's Mealtime Behaviors }\end{array}$ & $\begin{array}{c}4=\text { strongly disagree } \\
20=\text { strongly agree }\end{array}$ & 56 & 8.0 & 5.0 & 16.0 & 4.0 \\
\hline $\begin{array}{l}\text { Influence of Child's Food } \\
\text { Preferences on What Other } \\
\text { Family Members Eat }\end{array}$ & $\begin{array}{c}3=\text { strongly disagree } \\
15=\text { strongly agree }\end{array}$ & 38 & 6.0 & 4.0 & 10.0 & 3.0 \\
\hline
\end{tabular}

Table 7. Descriptive Statistics of Mealtime Construct Scores 


\section{Occurrence of Problematic Mealtime Behaviors}

The frequency of child mealtime behaviors reported by parents was assessed by parent responses to the questions in the "Occurrence of Problematic Behaviors" construct. The distribution of responses to the 12 problematic mealtime behaviors that were included in the MOHQ is displayed in Figure 1. To determine which behaviors were reported to occur most often, the number of respondents that selected often or very often for each behavior were counted. The distribution of data is displayed in Figure 2.

The most frequent problematic child mealtime behaviors reported by parents were that their child squirms or fidgets while eating (31\%), refuses to try new foods (31\%) and is picky about the food he or she will eat (37\%). Two of the three problematic mealtime behaviors reported to be occurring most frequently were the two questions that were added regarding picky eating: my child refuses to try new foods", and "my child is picky about the food he or she will eat". Of the 23 parents that reported their child was often/very often picky about the foods they will eat, 13 were age three, 8 were age four and only 2 were age five. Also, of the 19 respondents that reported their child refuses to try new foods often/very often, 12 were age three, 5 were age four and only 2 were age five. 


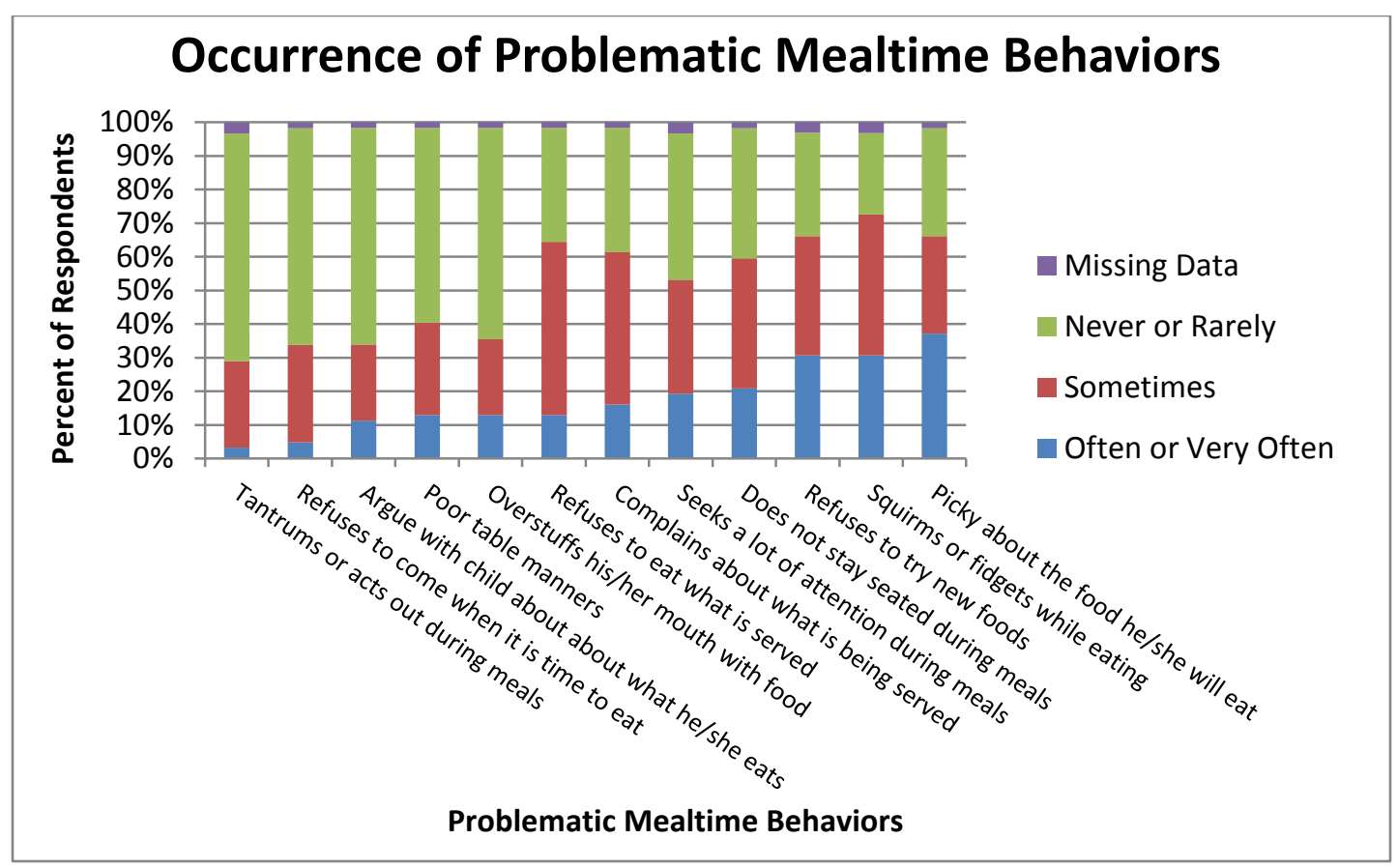

Figure 4. Occurrence of Problematic Mealtime Behaviors 


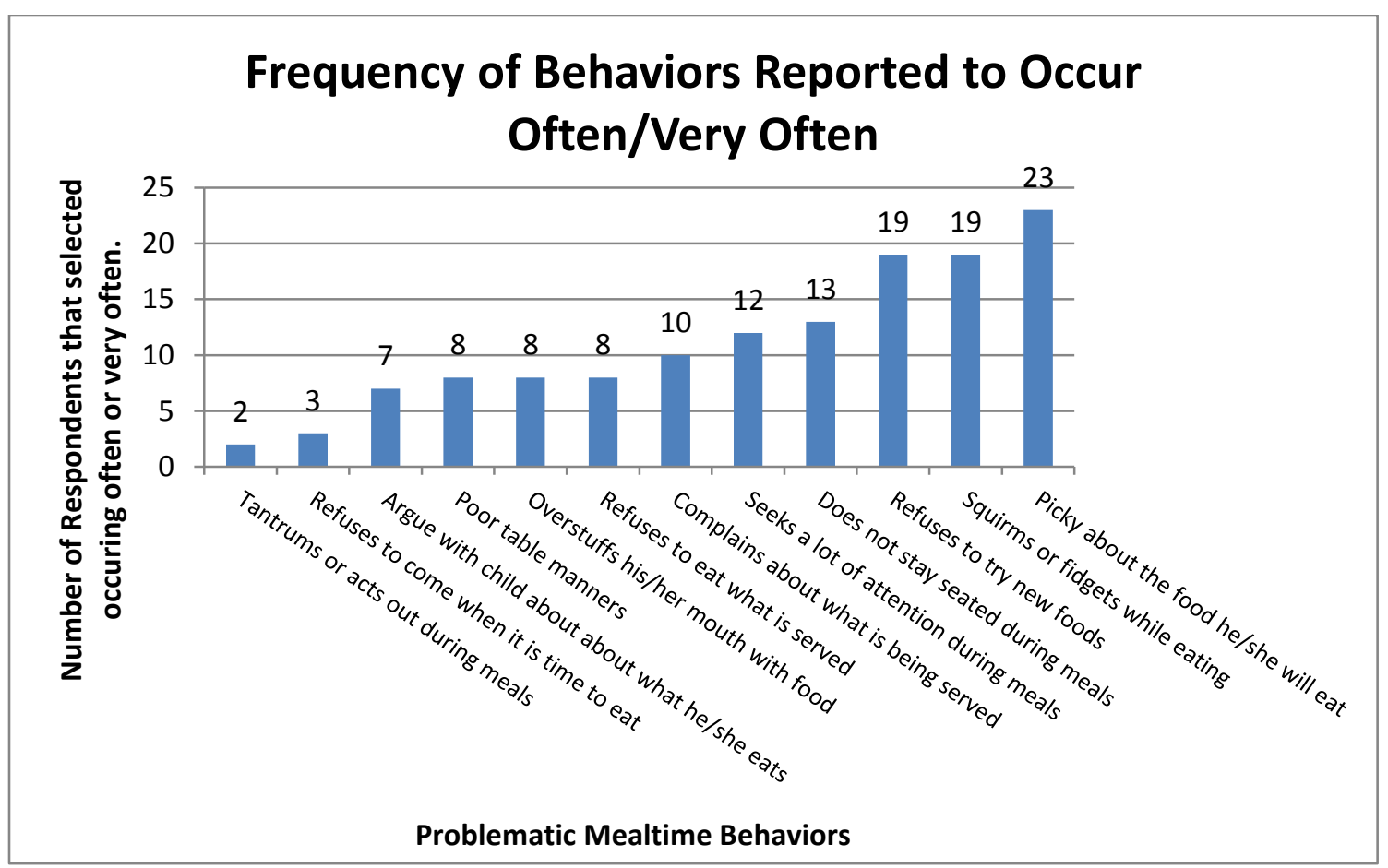

Figure 5. Frequency of Behaviors Reported to Occur Often/Very Often

\section{Variety of Foods Consumed}

Overall, the mean number of foods consumed weekly was $38.9 \pm 11.7$ with a minimum of 22 foods consumed and a maximum of 71 foods consumed. The distribution of data is displayed in Figure 3 with regards to the child's gender and age. Females consumed on average four more foods per week then males, but this difference was not statistically significant. Three and four year olds consumed a similar number of foods per week, whereas children age five consumed on average 11 more foods. Although there was an observable increase in the total number of foods consumed from age four to five, the difference between the three groups was not statistically significant. 


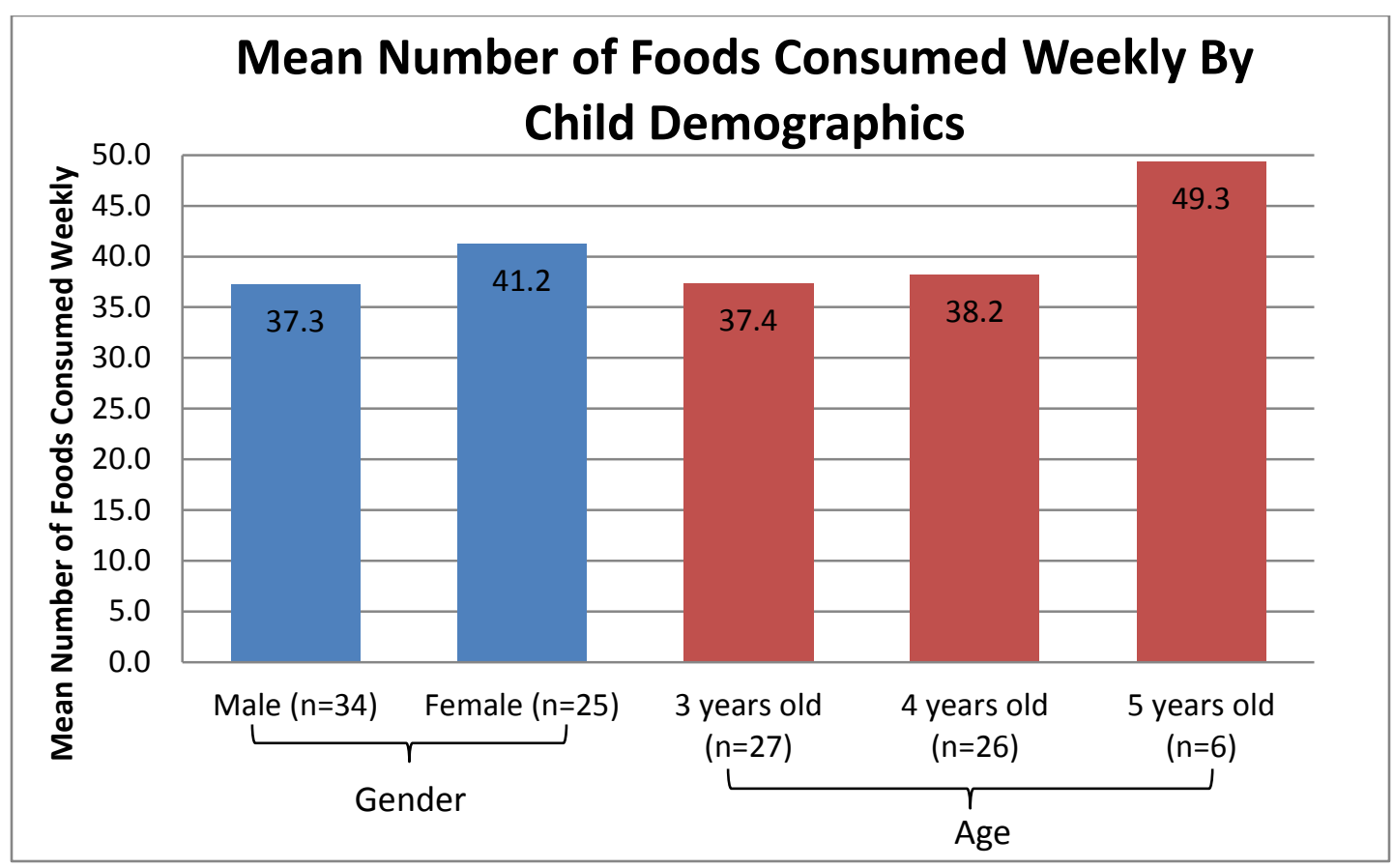

Figure 6. Mean Number of Foods Consumed Weekly by Child Demographics

\section{Relationships between Parent Concern and Diet Variety}

Spearman correlation coefficients and p-values for the relationships between the child mealtime constructs and the number of foods consumed are reported in Table 4.

Overall, Spearman correlation showed no correlation between "Parent Concern about Child's Diet" and the total number of foods consumed by the child $(r=.005$, $\mathrm{p}=.968$ ). Additionally, Spearman correlation showed no correlation between "Parental Concern about Child's Mealtime Behavior" and the total number of foods consumed by the child $(\mathrm{r}=.084, \mathrm{p}=.550) .($ Table 4$)$ 


\begin{tabular}{|c|c|c|c|c|c|c|c|}
\hline \multicolumn{8}{|c|}{$\begin{array}{c}\text { Correlational Analysis of Weekly Number of Foods Consumed and Child } \\
\text { Mealtime Constructs Using Spearman Correlation Coefficients }\end{array}$} \\
\hline & $\begin{array}{l}\text { Weekly } \\
\text { Number } \\
\text { of Foods } \\
\text { Consumed }\end{array}$ & $\begin{array}{l}\text { Child's } \\
\text { Influence }\end{array}$ & $\begin{array}{l}\text { Spousal } \\
\text { Stress }^{a}\end{array}$ & $\begin{array}{l}\text { Parent } \\
\text { Concern } \\
\text { about } \\
\text { Child's } \\
\text { Diet } \\
\end{array}$ & $\begin{array}{l}\text { Use of } \\
\text { Food as } \\
\quad \text { a } \\
\text { Reward }\end{array}$ & $\begin{array}{l}\text { Parent } \\
\text { Concern } \\
\text { about } \\
\text { Behaviors }\end{array}$ & $\begin{array}{c}\text { Occurrence } \\
\text { of Problem } \\
\text { Behaviors }\end{array}$ \\
\hline Structure of Family Meals & $.356^{* *}$ & -.081 & -.231 & -.252 & .118 & .030 & -.205 \\
\hline $\begin{array}{l}\text { Occurrence of Problem } \\
\text { Behaviors }\end{array}$ & .011 & .264 & $.522^{* *}$ & $.509^{* *}$ & .160 & $.683^{* *}$ & \\
\hline $\begin{array}{l}\text { Parent Concern about } \\
\text { Behaviors }\end{array}$ & .084 & .194 & $.387^{* *}$ & $.539^{* *}$ & .248 & & \\
\hline Use of Food as a Reward & .138 & .283 & .063 & .126 & & & \\
\hline $\begin{array}{l}\text { Parent Concern about } \\
\text { Child's Diet }\end{array}$ & .005 & $.375^{*}$ & .254 & & & & \\
\hline Spousal Stress ${ }^{a}$ & $.280^{*}$ & $.325^{*}$ & & & & & \\
\hline Child's Influence $^{b}$ & $.388^{*}$ & & & & & & \\
\hline \multicolumn{8}{|c|}{$\begin{array}{l}\text { **. Correlation is significant at the } 0.01 \text { level (2-tailed). } \\
\text { *. Correlation is significant at the } 0.05 \text { level ( } 2 \text {-tailed). } \\
{ }^{\mathrm{a}} \text { Spousal Stress Related to Child's Mealtime Behaviors } \\
{ }^{b} \text { Influence of Child Food Preferences on what other Fan }\end{array}$} \\
\hline
\end{tabular}

Table 8. Correlational Analysis of Weekly Number of Foods Consumed and Child Mealtime Constructs Using Spearman Correlation Coefficients

\section{Relationships between Child Mealtime Constructs}

The relationship between the five additional child mealtime constructs and the total number of foods consumed were also assessed using Spearman correlation coefficients. There was a statistically significant correlation between the total number of foods consumed and the "Structure of Family Meals" $(\mathrm{r}=.356)$, "Spousal Stress Related to Child's Mealtime Behavior" $(\mathrm{r}=.280)$ and "Influence of Child's Food Preferences" ( $\mathrm{r}$ $=.388)$.

Additionally, the relationships between each of the seven child mealtime constructs were assessed. The "Occurrence of Problematic Mealtime Behaviors" construct was shown to have a moderate to strong statistically significant correlation with 
"Parent Concern about Mealtime Behaviors" ( $\mathrm{r}=.683)$, "Spousal Stress Related to Child's Mealtime Behaviors" $(\mathrm{r}=.522)$ and "Parental Concern about Child's Diet" $(\mathrm{r}=$ $.509)$.

"Parent Concern about Mealtime Behaviors" was also shown to have a statistically significant correlation with "Parental Concern about Child's Diet" $(r=.539)$ and "Spousal Stress Related to Child's Mealtime Behaviors" $(\mathrm{r}=.387)$. The "Influence of Child's Food Preferences" was shown to be correlated with "Parental Concern about Child's Diet" $(r=.375)$ and "Spousal Stress Related to Child's Mealtime Behaviors" $(\mathrm{r}=.325)$. Both correlations were statistically significant.

\section{Parent Perceptions of Picky Eating Behaviors}

To assess parent perceptions of picky eating behaviors, the relationship between the question "my child is a picky eater" and the other questions related to picky eating within the "Parent Concern about Child's Diet" were assessed using Spearman Correlation Coefficients. Higher levels of concern on "my child is a picky eater" were strongly correlated with higher levels of concern "my child does not eat a variety of foods" $(\mathrm{r}=.726)$, "my child will not try new foods" $(\mathrm{r}=.650)$, "my child is not flexible about what he/she eats" $(\mathrm{r}=.640)$ and "my child eats only a few types of food $(\mathrm{r}=.715)$.

Additionally, the relationship between "my child is picky about the food he/she will eat" and the other questions related to picky eating within the "Problematic Child Mealtime Behaviors" construct were assessed using Spearman Correlation Coefficients. Higher frequency of occurrence on "my child is picky about the food he/she will eat" was correlated with higher frequency on "my child refuses to try new foods" $(\mathrm{r}=.771)$, "my 
child complains about what is being served" $(\mathrm{r}=.639)$, "I argue with my child about what he/she eats" $(\mathrm{r}=.403)$, and "my child refuses to eat what is served" $(\mathrm{r}=.659)$.

\section{DISCUSSION}

This study found two of the most frequently reported problematic child mealtime behaviors by parents to be that their child refuses to try new foods and is picky about the food he or she will eat. This suggests that parents may associate the refusal of new foods with picky eating which is consistent with past research that has found unwillingness to try new foods as one of the common behaviors reported by mothers in regards to picky eating. $5,7-10$

Of the parents that reported their child was often/very often picky about the foods he/she will eat, the majority were age three, a few were age four and even less were age five. The same was true for those respondents that reported their child refuses to try new foods. Additionally, it was found that three and four year olds consumed a similar number of foods per week, whereas children age five consumed on average 11 more foods. Although the difference between the groups was not statistically significant, this data is consistent with past research and suggests that picky eating behaviors in typically

developing children may decrease with age and increased exposure. ${ }^{10,11,21,26}$ Regarding gender, females consumed four more foods on average per week then males, but this was not a significant difference. This is also consistent with past research and suggests that picky eating behaviors is equally prevalent in young males and females. ${ }^{7,11}$ 
No correlation was found between parental concern about their child's diet and the variety of foods consumed by the child. This suggests that parent concern about what the child is consuming does not accurately reflect the quantity and variety of foods the child is consuming. A few of the children whose parents reported a high level of concern regarding their behavior were still consuming well above the average number of foods per week for our sample and a few who reported low levels of concern were consuming well below the average. One possible explanation for this is that parents that are more concerned with their child's diet may intervene more in an attempt to get their child to consume more foods. This has been shown in past research that has found parents who perceive their child to be picky eaters to be more likely to pressure their child to eat or use alternative methods such as offering food as a reward, preparing separate meals for the child or allowing distractions during meals. ${ }^{7-9,44,49}$ In contrast, there are many potential reasons that parents may not be concerned about their child's diet including a lack of knowledge regarding age appropriate diet recommendations, an assumption that the child is just being difficult or that the parent has a lack of variety in their own diet resulting in limited food choices for the child.

Higher levels of "Parent Concern about Mealtime Behavior" were positively correlated with the "Occurrence of Problematic Mealtime Behaviors" which implies that parent level of concern is appropriately elevated with an increased occurrence of problematic behaviors. However, there was no significant correlation between "Parental Concern about Mealtime Behaviors" and the total number of foods consumed by the child. This suggests that parent concern about mealtime behaviors does not accurately 
represent the child's diet variety. Similarly, we found no correlation between "Occurrence of Problematic Mealtime Behaviors" and the total number of foods consumed which suggests that the occurrence of problematic mealtime behaviors is not affecting the variety of foods the child is consuming. Despite this lack of correlation between mealtime behaviors and the total number of foods consumed, it is important to consider that a high occurrence of problematic mealtime behaviors can cause greater parent frustration which could result in negative effects on the child's future intake and food preferences. ${ }^{44,49,50}$

There were correlations between other child mealtime behavior constructs and the number of weekly foods consumed. The correlation between the total number of foods consumed and the "Structure of Family Meals" is consistent with other research linking regular family meals with beneficial health and nutrition outcomes in children and adolescents. ${ }^{31,85-89}$ More specifically, the parents that reported having family meals closely aligned to traditional family-style meals (ex. sitting at the table with family, without television, eating home-cooked meals, etc.) were consuming a greater total number of foods. The correlation between the total number of foods consumed and the "Influence of Child's Food Preferences" construct should be interpreted cautiously because only those with both a spouse and multiple children were included so the sample size was much smaller $(\mathrm{n}=38)$.

High levels of "Spousal Stress Related to Child's Mealtime Behaviors" were shown to be positively correlated with multiple other mealtime behaviors. It is important to consider that the level of spousal stress related to the child's mealtime behaviors is a 
representation of how the parent respondent believes their child's behaviors are affecting their spouse and is likely perceived as being similar to their own level of stress and concern.

Additionally, "Parent concern about child's diet was positively correlated with both the "Occurrence of Problematic Mealtime Behaviors" and "Parent Concern about Mealtime Behaviors". This implies that parent concerns regarding diet and behaviors are similar and one may possibly influence the other. This study supports past research regarding picky eating behaviors reported by parents in that parents in our sample who perceived their child to be a picky eater were also concerned that their child does not eat a variety of foods, will not try new foods, complains about what is served, is not flexible about what he/she eats, and eats only a few types of food. ${ }^{5,7-10}$

\section{Limitations}

This study was limited to parents of preschool children ages 3-5 and is not generalizable to children in other age groups. In addition, this study was conducted using a convenience sample at a university child care program which is not representative of all preschool programs. The majority of parent respondents were married, white females with a bachelor's degree or higher so the results of this study are likely not representative of male parents or those with lower education levels. A further limitation of the study is that The Meals in Our Household Questionnaire is subject to social desirability bias and participants may differ in their levels of understanding and interpreting the questionnaires. The FFQ is also subject to bias in that participants may overestimate foods they believe to be healthy. Because this study was not concerned with portion sizes 
overestimation should have little effect on the results. In addition, the FFQ only assessed diet variety over a one week period which could be dependent on the foods the child was offered that particular week and may not be representative of all the foods that the child consumes and. Also, the foods listed on the FFQ may not be reflective of the dietary patterns of all participants and ethnic differences in food selection may not be captured.

\section{IMPLICATIONS FOR RESEARCH AND PRACTICE}

This study has important implications on nutrition assessment in children. Health professionals often must rely on parent report to assess a child's eating behaviors and diet quality. If there are no obvious signs of malnutrition, clinicians may simply ask parents whether or not they have any nutrition concerns about their child and if none are present, they generally do not proceed with nutrition assessment. Often, parents will say that their child is a "picky eater" and be told that they will "grow out of it". Although this is true for most children, some children may have a more serious feeding problem and the difference in interpretation of "picky eating" makes this difficult to assess without additional questioning. This study has also demonstrated that the level of parent concern regarding their child's mealtime behaviors and diet may not be good measures of how the child is actually eating. Thus, it is important that clinicians do not simply rely on broad overall nutrition questions to assess the child's eating habits. Although children whose parents express high levels of concern about their child's eating habit are typically referred to a Registered Dietitian for assessment, there appears to be little nutrition 
assessment conducted with parents who express little concern. More specific questioning regarding mealtime behaviors, as well as gathering an overall picture of the child's diet through a food frequency questionnaire or 3-day food record, may be necessary to determine the actual severity of the child's behaviors and diet variety.

Additional research is needed to better assess the reliability of parent perceptions of their child's eating behaviors and diet variety. Future research should include a more demographically diverse sample. A multi-site study with participants from more than one preschool or day care center may be helpful in increasing sample size and demographic diversity. There is also a need for research in clinical settings to determine how health professionals typically respond to parent concerns about their child's eating habits and diet. Because various interpretations of picky eating continue to exist, standardized methods for questions regarding eating behaviors and diet should be developed to help clinicians better assess the child's nutrition status. 


\section{References}

1. Fraker C. Food chaining: The proven 6-step plan to stop picky eating, solve feeding problems, and expand your child's diet. New York: Marlowe; 2007.

2. Birch LL. The role of experience in children's food acceptance patterns. J Am Diet Assoc. 1987;87(9 Suppl):S36-40.

3. Birch LL, Fisher JA. Appetite and eating behavior in children. Pediatr Clin North Am. 1995;42(4):931-953.

4. Birch LL, Fisher JO. Development of eating behaviors among children and adolescents. Pediatrics. 1998;101(Supplement 2):539-549.

5. Carruth BR, Skinner J, Houck K, Moran J 3rd, Coletta F, Ott D. The phenomenon of "picky eater": a behavioral marker in eating patterns of toddlers. J Am Coll Nutr. 1998;17(2):180186.

6. Galloway AT, Fiorito L, Lee Y, Birch LL. Parental pressure, dietary patterns, and weight status among girls who are "picky eaters." J Am Diet Assoc. 2005;105(4):541-548. doi:10.1016/j.jada.2005.01.029.

7. Jacobi C, Schmitz G, Agras WS. Is picky eating an eating disorder? Int J Eat Disord. 2008;41(7):626-634. doi:10.1002/eat.20545.

8. Jacobi C, Agras WS, Bryson S, Hammer LD. Behavioral validation, precursors, and concomitants of picky eating in childhood. J Am Acad Child Adolesc Psychiatry. 2003;42(1):76-84. doi:10.1097/00004583-200301000-00013.

9. Mascola AJ, Bryson SW, Agras WS. Picky eating during childhood: A longitudinal study to age 11 years. Eat Behav. 2010;11(4):253-257. doi:10.1016/j.eatbeh.2010.05.006.

10. Nicholls D, Bryant-Waugh R. Eating disorders of infancy and childhood: Definition, symptomatology, epidemiology, and comorbidity. Child Adolesc Psychiatr Clin N Am. 2009;18(1):17-30. doi:10.1016/j.chc.2008.07.008.

11. Benjasuwantep B, Chaithirayanon S, Eiamudomkan M. Feeding problems in healthy young children: prevalence, related factors and feeding practices. Pediatr Rep. 2013;5(2). doi:10.4081/pr.2013.e10.

12. Bandini LG, Anderson SE, Curtin C, et al. Food selectivity in children with autism spectrum disorders and typically developing children. J Pediatr. 2010;157(2):259-264. doi:10.1016/j.jpeds.2010.02.013. 
13. Bryant-Waugh R, Markham L, Kreipe RE, Walsh BT. Feeding and eating disorders in childhood. Int J Eat Disord. 2010;43(2):98 - 111.

14. Kreipe RE, Palomaki A. Beyond picky eating: Avoidant/restrictive food intake disorder. Curr Psychiatry Rep. 2012;14(4):421-431. doi:10.1007/s11920-012-0293-8.

15. Dovey TM, Farrow CV, Martin CI, Isherwood E, Halford JCG. When does food refusal require professional intervention? Curr Nutr Food Sci. 2009;5(3):160-171. doi:10.2174/157340109789007162.

16. Ünlü G, Aras S, Eminagaoglu N, Büyükgebiz B, Bekem Ö. Developmental characteristics of children aged 1-6 years with food refusal. Public Health Nurs. 2008;25(1):2-9.

17. Liu J, Raine A, Venables PH, Mednick SA. Malnutrition at age 3 years and externalizing behavior problems at ages 8, 11, and 17 years. Am J Psychiatry. 2004;161(11):2005-2013. doi:10.1176/appi.ajp.161.11.2005.

18. Manikam R, Perman JA. Pediatric feeding disorders. J Clin Gastroenterol January 2000. 2000;30(1):34-46.

19. Birch LL, Marlin DW. I don't like it; I never tried it: Effects of exposure on two-year-old children's food preferences. Appetite. 1982;3(4):353-360. doi:10.1016/S01956663(82)80053-6.

20. Birch LL. Effects of peer models' food choices and eating behaviors on preschoolers' food preferences. Child Dev. 1980;51(2):489-496. doi:10.2307/1129283.

21. Birch LL. Dimensions of preschool children's food preferences. J Nutr Educ. 1979;11(2):77-80. doi:10.1016/S0022-3182(79)80089-8.

22. Birch LL. Preschool children's food preferences and consumption patterns. J Nutr Educ. 1979;11(4):189-192. doi:10.1016/S0022-3182(79)80025-4.

23. Barker LM, Best MR, Domjan MP. Learning mechanisms in food selection. Baylor University Press; 1977.

24. Domjan M. Attenuation and enhancement of neophobia for edible substances. Learn Mech Food Sel. 1977:151-179.

25. Birch LL, Gunder L, Grimm-Thomas K, Laing DG. Infants' consumption of a new food enhances acceptance of similar foods. Appetite APPET. 1998;30(3):283-295.

26. Birch LL, McPhee L, Shoba BC, Pirok E, Steinberg L. What kind of exposure reduces children's food neophobia?: Looking vs. tasting. Appetite. 1987;9(3):171-178. doi:10.1016/S0195-6663(87)80011-9.

27. Galloway AT, Lee Y, Birch LL. Predictors and consequences of food neophobia and pickiness in young girls. J Am Diet Assoc. 2003;103(6):692-698. doi:10.1053/jada.2003.50134. 
28. Russell CG, Worsley A. A population-based study of preschoolers' food neophobia and its associations with food preferences. J Nutr Educ Behav. 2008;40(1):11-19. doi:10.1016/j.jneb.2007.03.007.

29. Koivisto U-K, Fellenius J, Sjödén P-O. Relations between parental mealitime practices and children's food intake. Appetite. 1994;22(3):245-258. doi:10.1006/appe.1994.1023.

30. Sweetman C, McGowan L, Croker H, Cooke L. Characteristics of Family Mealtimes Affecting Children's Vegetable Consumption and Liking. J Am Diet Assoc. 2011;111(2):269-273. doi:10.1016/j.jada.2010.10.050.

31. Gillman MW, Rifas-Shiman SL, Frazier AL, et al. Family Dinner and Diet Quality Among Older Children and Adolescents. Arch Fam Med. 2000;9(3):235. doi:10.1001/archfami.9.3.235.

32. Birch LL. The relationship between children's food preferences and those of their parents. J Nutr Educ. 1980;12(1):14-18. doi:10.1016/S0022-3182(80)80249-4.

33. Marchi M, Cohen P. Early childhood eating behaviors and adolescent eating disorders. J Am Acad Child Adolesc Psychiatry. 1990;29(1):112-117. doi:10.1097/00004583199001000-00017.

34. Field D, Garland M, Williams K. Correlates of specific childhood feeding problems. J Paediatr Child Health. 2003;39(4):299-304. doi:10.1046/j.1440-1754.2003.00151.x.

35. Kral TVE, Eriksen WT, Souders MC, Pinto-Martin JA. Eating behaviors, diet quality, and gastrointestinal symptoms in children with autism spectrum disorders: A brief review. J Pediatr Nurs. doi:10.1016/j.pedn.2013.01.008.

36. Ahearn WH, Castine T, Nault K, Green G. An assessment of food acceptance in children with autism or pervasive developmental disorder-not otherwise specified. J Autism Dev Disord. 2001;31(5):505-511.

37. Cermak SA, Curtin C, Bandini LG. Food selectivity and sensory sensitivity in children with autism spectrum disorders. J Am Diet Assoc. 2010;110(2):238-246.

doi:10.1016/j.jada.2009.10.032.

38. Martins Y, Young RL, Robson DC. Feeding and eating behaviors in children with autism and typically developing children. J Autism Dev Disord. 2008;38(10):1878-1887. doi:10.1007/s10803-008-0583-5.

39. Williams K, Gibbons B, Schreck K. Comparing selective eaters with and without developmental disabilities. J Dev Phys Disabil. 2005;17(3):299-309. doi:10.1007/s10882005-4387-7.

40. Carruth BR, Ziegler PJ, Gordon A, Barr SI. Prevalence of picky eaters among infants and toddlers and their caregivers' decisions about offering a new food. J Am Diet Assoc. 2004;104, Supplement 1:57-64. doi:10.1016/j.jada.2003.10.024. 
41. Crist W, Napier-Phillips A. Mealtime behaviors of young children: A comparison of normative and clinical data. J Dev. 2001;22(5):279-286.

42. Cooke LJ, Wardle J. Age and gender differences in children's food preferences. Br J Nutr. 2005;93(5):741-746.

43. Evans A, Seth JG, Smith S, et al. Parental feeding practices and concerns related to child underweight, picky eating, and using food to calm differ according to ethnicity/race, acculturation, and income. Matern Child Health J. 2011;15(7):899-909. doi:10.1007/s10995-009-0526-6.

44. Galloway AT, Fiorito LM, Francis LA, Birch LL. "Finish your soup": Counterproductive effects of pressuring children to eat on intake and affect. Appetite. 2006;46(3):318-323. doi:10.1016/j.appet.2006.01.019.

45. American Psychiatric Association, Task Force on DSM-IV. Diagnostic and statistical manual of mental disorders: DSM-IV-TR. Washington, DC: American Psychiatric Association; 2000.

46. American Psychiatric Association, DSM-5 Task Force. Diagnostic and statistical manual of mental disorders: DSM-5. Arlington, Va.: American Psychiatric Association; 2013.

47. Burklow KA, Phelps AN, Schultz JR, McConnell K, Rudolph C. Classifying complex pediatric feeding disorders. J Pediatr Gastroenterol. 1998;27(2):143-147.

48. Kerzner B. Clinical investigation of feeding difficulties in young children: A practical approach. Clin Pediatr (Phila). 2009;48(9):960-965. doi:10.1177/0009922809336074.

49. Faith MS, Storey M, Kral TVE, Pietrobelli A. The feeding demands questionnaire: assessment of parental demand cognitions concerning parent-child feeding relations. J Am Diet Assoc. 2008;108(4):624-630. doi:10.1016/j.jada.2008.01.007.

50. Hafstad GS, Abebe DS, Torgersen L, von Soest T. Picky eating in preschool children: The predictive role of the child's temperament and mother's negative affectivity. Eat Behav. 2013;14(3):274-277. doi:10.1016/j.eatbeh.2013.04.001.

51. Fishbein M, Cox S, Swenny C, Mogren C, Walbert L, Fraker C. Food chaining: A systematic approach for the treatment of children with feeding aversion. Nutr Clin Pract. 2006;21(2):182-184. doi:10.1177/0115426506021002182.

52. Babbitt R, Hoch T. Behavioral assessment and treatment of pediatric feeding disorders. J Dev Behav Pediatr JDBP. 1994;15(4):278-91.

53. Budd KS, McGraw TE, Farbisz R, et al. Psychosocial concomitants of children's feeding disorders. J Pediatr Psychol. 1992;17(1):81-94. doi:10.1093/jpepsy/17.1.81.

54. Wright CM, Parkinson KN, Shipton D, Drewett RF. How do toddler eating problems relate to their eating behavior, food preferences, and growth? Pediatrics. 2007;120(4):e1069e1075. doi:10.1542/peds.2006-2961. 
55. Dubois L, Farmer AP, Girard M, Peterson K. Preschool children's eating behaviours are related to dietary adequacy and body weight. Eur J Clin Nutr. 2007;61(7):846-855. doi:10.1038/sj.ejen.1602586.

56. Dovey TM, Staples PA, Gibson EL, Halford JCG. Food neophobia and "picky/fussy" eating in children: A review. Appetite. 2008;50(2-3):181-193. doi:10.1016/j.appet.2007.09.009.

57. Cooke L, Carnell S, Wardle J. Food neophobia and mealtime food consumption in 4-5 year old children. Int J Behav Nutr Phys Act. 2006;3:14. doi:10.1186/1479-5868-3-14.

58. Liu J, Raine A. The effect of childhood malnutrition on externalizing behavior. Curr Opin Pediatr. 2006;18(5):565-570. doi:10.1097/01.mop.0000245360.13949.91.

59. Galler J. Behavioral consequences of malnutrition in early life. Hum Nutr Compr Treatise. 1984;5. Available at: http://agris.fao.org/agrissearch/search/display.do?f=2012/OV/OV201204184004184.xml;US19850072637. Accessed September 17, 2013.

60. Barrett DE, Radke-Yarrow M, Klein RE. Chronic malnutrition and child behavior: Effects of early caloric supplementation on social and emotional functioning at school age. Dev Psychol. 1982;18(4):541-556.

61. Martorell R. The nature of child malnutrition and its long-term implications. Food Nutr Bull. 1999;20(3):288-292.

62. Ekstein S, Laniado D, Glick B. Does picky eating affect weight-for-length measurements in young children? Clin Pediatr (Phila). 2010;49(3):217-220. doi:10.1177/0009922809337331.

63. Hendy HM, Williams KE, Riegel K, Paul C. Parent mealtime actions that mediate associations between children's fussy-eating and their weight and diet. Appetite. 2010;54(1):191-195. doi:10.1016/j.appet.2009.10.006.

64. Lockner DW, Crowe TK, Skipper BJ. Dietary Intake and Parents' Perception of Mealtime Behaviors in Preschool-Age Children with Autism Spectrum Disorder and in Typically Developing Children. J Am Diet Assoc. 2008;108(8):1360-1363. doi:10.1016/j.jada.2008.05.003.

65. Schreck KA, Williams K. Food preferences and factors influencing food selectivity for children with autism spectrum disorders. Res Dev Disabil. 2006;27(4):353-363. doi:10.1016/j.ridd.2005.03.005.

66. Birch L., Fisher J., Grimm-Thomas K, Markey C., Sawyer R, Johnson S. Confirmatory factor analysis of the Child Feeding Questionnaire: a measure of parental attitudes, beliefs and practices about child feeding and obesity proneness. Appetite. 2001;36(3):201-210. doi:10.1006/appe.2001.0398.

67. Costanzo PR, Woody EZ. Domain-specific parenting styles and their impact on the child's development of particular deviance: The example of obesity proneness. J Soc Clin Psychol. 1985;3(4):425-445. doi:10.1521/jscp.1985.3.4.425. 
68. Wardle J, Guthrie CA, Sanderson S, Rapoport L. Development of the Children's Eating Behaviour Questionnaire. J Child Psychol Psychiatry. 2001;42(7):963-970. doi:10.1111/1469-7610.00792.

69. Tharner A, Jansen PW, Jong JCK, et al. Toward an operative diagnosis of fussy/picky eating: a latent profile approach in a population-based cohort. Int J Behav Nutr Phys Act. 2014;11(1):14. doi:10.1186/1479-5868-11-14.

70. Hendy HM, Williams KE, Camise TS, Eckman N, Hedemann A. The Parent Mealtime Action Scale (PMAS). Development and association with children's diet and weight. Appetite. 2009;52(2):328-339.

71. Anderson SE, Must A, Curtin C, Bandini LG. Meals in our household: reliability and initial validation of a questionnaire to assess child mealtime behaviors and family mealtime environments. J Acad Nutr Diet. 2012;112(2):276-284. doi:10.1016/j.jada.2011.08.035.

72. Parrish LA, Marshall JA, Krebs NF, Rewers M, Norris JM. Validation of a food frequency questionnaire in preschool children. Epidemiology. 2003;14(2):213-217. doi:10.1097/01.EDE.0000041256.12192.23.

73. Treiber FA, Leonard SB, Frank G, et al. Dietary assessment instruments for preschool children: reliability of parental responses to the 24-hour recall and a food frequency questionnaire. J Am Diet Assoc. 1990;90(6):814-822.

74. Blum RE, Wei EK, Rockett HRH, et al. Validation of a food frequency questionnaire in native american and caucasian children 1 to 5 years of age. Matern Child Health J. 1999;3(3):167-172. doi:10.1023/A:1022350023163.

75. Kobayashi T, Kamimura M, Imai S, et al. Reproducibility and validity of the food frequency questionnaire for estimating habitual dietary intake in children and adolescents. Nutr J. 2011;10(1):27. doi:10.1186/1475-2891-10-27.

76. Jarman M, Fisk CM, Ntani G, et al. Assessing diets of 3-year-old children: Evaluation of an FFQ. Public Health Nutr. 2013;FirstView:1-9. doi:10.1017/S136898001300102X.

77. Boyle MA, Holben DH. Community nutrition in action: An entrepreneurial approach. Belmont, CA: Wadsworth, Cengage Learning; 2010.

78. Archer LA, Rosenbaum PL, Streiner DL. The Children's Eating Behavior Inventory: Reliability and Validity Results. J Pediatr Psychol. 1991;16(5):629-642. doi:10.1093/jpepsy/16.5.629.

79. Wei E, Gardner J, Field A, Rosner B, Colditz G, Suitor C. Validity of a food frequency questionnaire in assessing nutrient intakes of low-income pregnant women. Matern Child Health J. 1999;3(4):241-246.

80. Baer HJ, Blum RE, Rockett HR, et al. Use of a food frequency questionnaire in American Indian and Caucasian pregnant women: a validation study. BMC Public Health. 2005;5:135. doi:10.1186/1471-2458-5-135. 
81. Suitor CJ, Gardner J, Willett WC. A comparison of food frequency and diet recall methods in studies of nutrient intake of low-income pregnant women. J Am Diet Assoc. 1989;89(12):1786-1794.

82. Willett WC SL, Stampfer MJ, Rosner B, Bain C, Witschi J, Hennekens CH, Speizer FE. Reproducibility and validity of a semiquantitative food frequency questionnaire. Am J Epidemiol. 1985;122(1):51-65.

83. United States, Department of Health and Human Services, United States, Department of Agriculture, United States, Dietary Guidelines Advisory Committee. Dietary guidelines for Americans, 2010. [Washington, D.C.]: U.S. Dept. of Health and Human Services, U.S. Dept. of Agriculture; 2010.

84. Freeland-Graves JH, Nitzke S. Position of the Academy of Nutrition and Dietetics: Total Diet Approach to Healthy Eating. J Acad Nutr Diet. 2013;113(2):307-317. doi:10.1016/j.jand.2012.12.013.

85. Neumark-Sztainer D, Hannan PJ, Story M, Croll J, Perry C. Family meal patterns: Associations with sociodemographic characteristics and improved dietary intake among adolescents. J Am Diet Assoc. 2003;103(3):317-322. doi:10.1053/jada.2003.50048.

86. Hammons AJ, Fiese BH. Is Frequency of Shared Family Meals Related to the Nutritional Health of Children and Adolescents? Pediatrics. 2011;127(6):e1565-e1574. doi:10.1542/peds.2010-1440.

87. Patrick H, Nicklas TA. A Review of Family and Social Determinants of Children's Eating Patterns and Diet Quality. J Am Coll Nutr. 2005;24(2):83-92. doi:10.1080/07315724.2005.10719448.

88. Fiese B, Foley, Kimberly, Spagnola, Mary. Routine and ritual elements in family mealtimes: Contexts for child well-being and family identity. New Dir Child Adolesc Dev. 2006;2006(111):67-89.

89. Fulkerson JA, Story M, Neumark-Sztainer D, Rydell S. Family Meals: Perceptions of Benefits and Challenges among Parents of 8- to 10-Year-Old Children. J Am Diet Assoc. 2008;108(4):706-709. doi:10.1016/j.jada.2008.01.005. 
Appendix:

\section{Research Packet Materials}




\section{Cover Letter}

\section{Dear Participant,}

My name is Evelyn Koski and I am a graduate student in the department of Medical Dietetics at The Ohio State University. For my thesis research I am examining parent perceptions of preschool children's mealtime behaviors and how they are related to the variety of foods the child consumes. Because your child is currently enrolled in a preschool classroom at the OSU Child Care Program, you are invited to participate in this research study by completing the attached surveys.

The following surveys have been developed to gather information about your child's mealtime behaviors and how often your child consumes certain foods each week. It is our hope that the data collected will provide useful information regarding the relationship between parent perceptions of their child's mealtime behaviors and the child's diet variety, which can be used to guide future interventions of childhood eating difficulties. There are no known risks to participating in this study.

The packet will require a total of approximately 20-30 minutes to complete. All study participants will be eligible to win one of four $\$ 25.00$ gift cards to Target. Please fill out the bottom portion of this sheet and your name will be entered into a random drawing that will occur after all surveys have been collected. The bottom of this sheet will be removed and placed in the drawing and will not be linked to your surveys in any way. To ensure that all data remains confidential, please do not put your name on any other survey pages. Participation is completely voluntary and you may refuse to participate at any time. If you choose to participate in this project, please answer all questions as honestly as possible and return the research packet in the sealed envelope provided to the designated box in your child's classroom by Friday, December 20th.

Thank you for taking the time to assist me in my educational endeavors. Return of this research packet will indicate your willingness to participate in this study. Copies of the final study will be provided to my faculty advisor, my thesis committee and the OSU Child Care Program administration. If you require additional information, have questions or would like to know the results of this study please contact me or my faculty advisor at the numbers listed below. For questions about your rights as a participant in this study or to discuss other study-related concerns or complaints with someone who is not part of the research team, you may contact Ms. Sandra Meadows in the Office of Responsible Research Practices at 1-800-678-6251.

Sincerely,

Evelyn Koski

koski.17@osu.edu

Dr. Marcia Nahikian-Nelms

Marcia.Nahikian-Nelms@osumc.edu

614-292-4758 


\section{Demographic Survey}

Please answer these questions about yourself:

1. What is your gender?

$\square$ Male
Female

2. How do you describe your ethnicity?

$\square$ White
$\square$ Hispanic or Latino
$\square$ Black or African American
$\square$ Native American or American Indian
$\square$ Asian/ Pacific Islander
$\square$ Other

3. What is your current marital status?

$\square$ Single
$\square$ Never Married
$\square$ Married or Domestic Partnership
$\square$ Widowed
$\square$ Divorced
$\square$ Separated

4. What is the highest level of education you have completed?
Elementary school
High School or Equivalent
Vocational/Technical School (2 yr)
Some College
Bachelor's Degree
Master's Degree
Doctoral Degree
Professional Degree (MD, JD, etc.)
Other

5. If applicable, what is the highest level of education completed by your spouse?

Elementary school

High School or Equivalent

Vocational/Technical School (2 yr)

Some College

Bachelor's Degree

Master's Degree

Doctoral Degree

Professional Degree (MD, JD, etc.)

Other
Please answer these questions about your child:

1. What is your child's gender?

$\square$ Male
$\square$ Female

2. What is your child's age?

3. How do you describe your child's ethnicity?

$\square$ White
$\square$ Hispanic or Latino
$\square$ Black or African American
$\square$ Native American or American Indian
$\square$ Asian/ Pacific Islander
$\square$ Other

4. How many siblings does your child have?
None, Only Child
One or Two
Three or Four
More than Four

5. If applicable, what is your child's birth order?

$\square$ Youngest Child
$\square$ Middle Child
$\square$ Oldest Child

6. Has your child been diagnosed with a developmental disability?

$\square$ No
$\square$ Yes
$\square$ If yes, please describe:




\section{Meals in Our Household Questionnaire}

\section{$\underline{\text { Meals in Our Household }}$}

DIRECTIONS: Please answer the questions below as they relate to you and your child who is between the ages of 3 and 11 years old. Please read and follow the directions above each set of questions. Thank you for taking time to be part of this study.

Part A: Mealtimes are different for different families. We are interested in what meals are like in your household. For each of the following items, please choose by checking one box in each row, how often the statement describes mealtimes with your child and/or in your household.

\begin{tabular}{|l|c|c|c|c|c|}
\hline & Never & Rarely & Sometimes & Often & $\begin{array}{c}\text { Always or } \\
\text { Almost Always }\end{array}$ \\
\hline $\begin{array}{l}\text { My child eats meals with myself or other } \\
\text { family members. }\end{array}$ & $\square$ & $\square$ & $\square$ & $\square$ & $\square$ \\
\hline $\begin{array}{l}\text { The television is on in the same room when } \\
\text { my child is eating meals. }\end{array}$ & $\square$ & $\square$ & $\square$ & $\square$ & $\square$ \\
\hline $\begin{array}{l}\text { Our family eats an evening meal at a regular } \\
\text { time (that is, we have a dinner-time). }\end{array}$ & $\square$ & $\square$ & $\square$ & $\square$ & $\square$ \\
\hline Meals in our household are rushed. & $\square$ & $\square$ & $\square$ & $\square$ & $\square$ \\
\hline We eat meals in the kitchen or dining room. & $\square$ & $\square$ & $\square$ & $\square$ & $\square$ \\
\hline $\begin{array}{l}\text { We eat meals in the family room or living } \\
\text { room. }\end{array}$ & $\square$ & $\square$ & $\square$ & $\square$ & $\square$ \\
\hline We eat meals in the car. & $\square$ & $\square$ & $\square$ & $\square$ & $\square$ \\
\hline $\begin{array}{l}\text { Everyone in our household eats something } \\
\text { different at meals. }\end{array}$ & $\square$ & $\square$ & $\square$ & $\square$ & $\square$ \\
\hline $\begin{array}{l}\text { At meals, my child eats the same food as } \\
\text { everyone else. }\end{array}$ & $\square$ & $\square$ & $\square$ & $\square$ & $\square$ \\
\hline We order 'take-out' for meals. & $\square$ & $\square$ & $\square$ & $\square$ & $\square$ \\
\hline We go out to eat at a restaurant. & $\square$ & $\square$ & $\square$ & $\square$ & $\square$ \\
\hline Someone in our household cooks meals. & $\square$ & $\square$ & $\square$ & $\square$ & $\square$ \\
\hline $\begin{array}{l}\text { My child chooses what he/she would like to } \\
\text { eat for meals. }\end{array}$ & $\square$ & $\square$ & $\square$ & $\square$ & $\square$ \\
\hline $\begin{array}{l}\text { We say grace or have a ritual at the start of } \\
\text { meals. }\end{array}$ & $\square$ & $\square$ & $\square$ & $\square$ & $\square$ \\
\hline $\begin{array}{l}\text { My child's food preferences influence what I, } \\
\text { myself, eat. }\end{array}$ & $\square$ & $\square$ & $\square$ & $\square$ & $\square$ \\
\hline $\begin{array}{l}\text { I ask my child to finish everything on his/her } \\
\text { plate. }\end{array}$ & $\square$ & $\square$ & $\square$ & $\square$ & $\square$ \\
\hline
\end{tabular}

Please turn the page 
Part B: Children's behavior at mealtimes can be an issue for parents and in families. Sometimes children behave well at meals and sometimes they could behave better. Parents also have different expectations for children's behavior at meals.

For each of the following statements, please choose how often the statement describes your child's behavior during the past 3 months, and for each statement choose how much of a problem that aspect of your child's behavior is for you. Please note that a behavior that occurs often may be a large problem in one family and may be not a problem or a small problem in another family. Likewise, a behavior that occurs rarely may be a large problem or may be not a problem.

My child refuses to come when it is time
to eat. $\quad$ check one box $\rightarrow$

How much of a problem is it for you that your child refuses to come when it is time to eat?

Not a problem Small problem Medium problem

Large problem check one box $\rightarrow$

My child has tantrums or acts out during meals. check one box $\rightarrow$

Never Rarely Sometimes Often Very Often How much of a problem is it for you that your child has tantrums or acts out during meals?

\section{check one box $\rightarrow \square$}

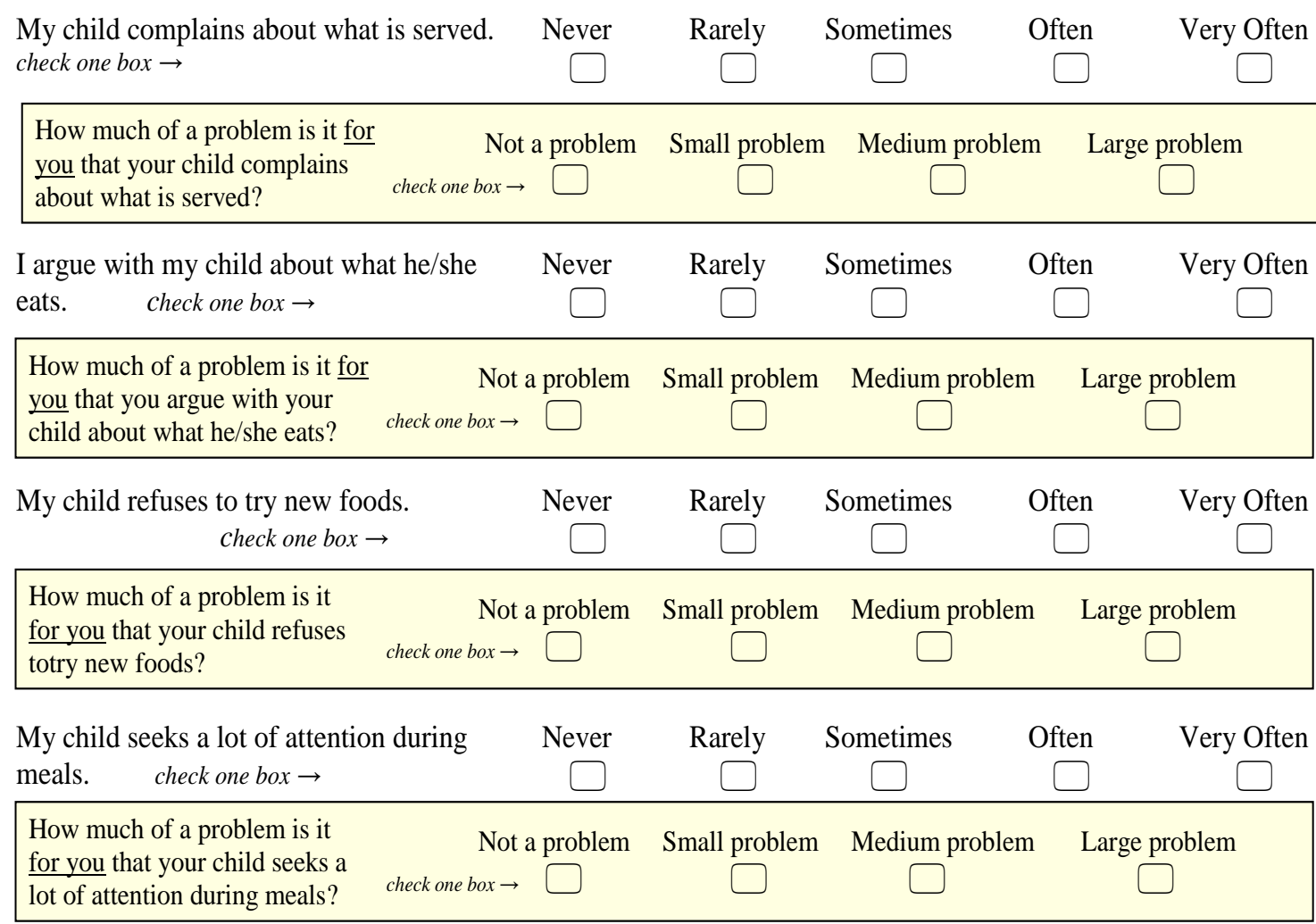


Part B: Continued. For each of the following statements, please choose how often the statement describes your child's behavior during the past 3 months, and for each statement choose how much of a problem that aspect of your child's behavior is for you.

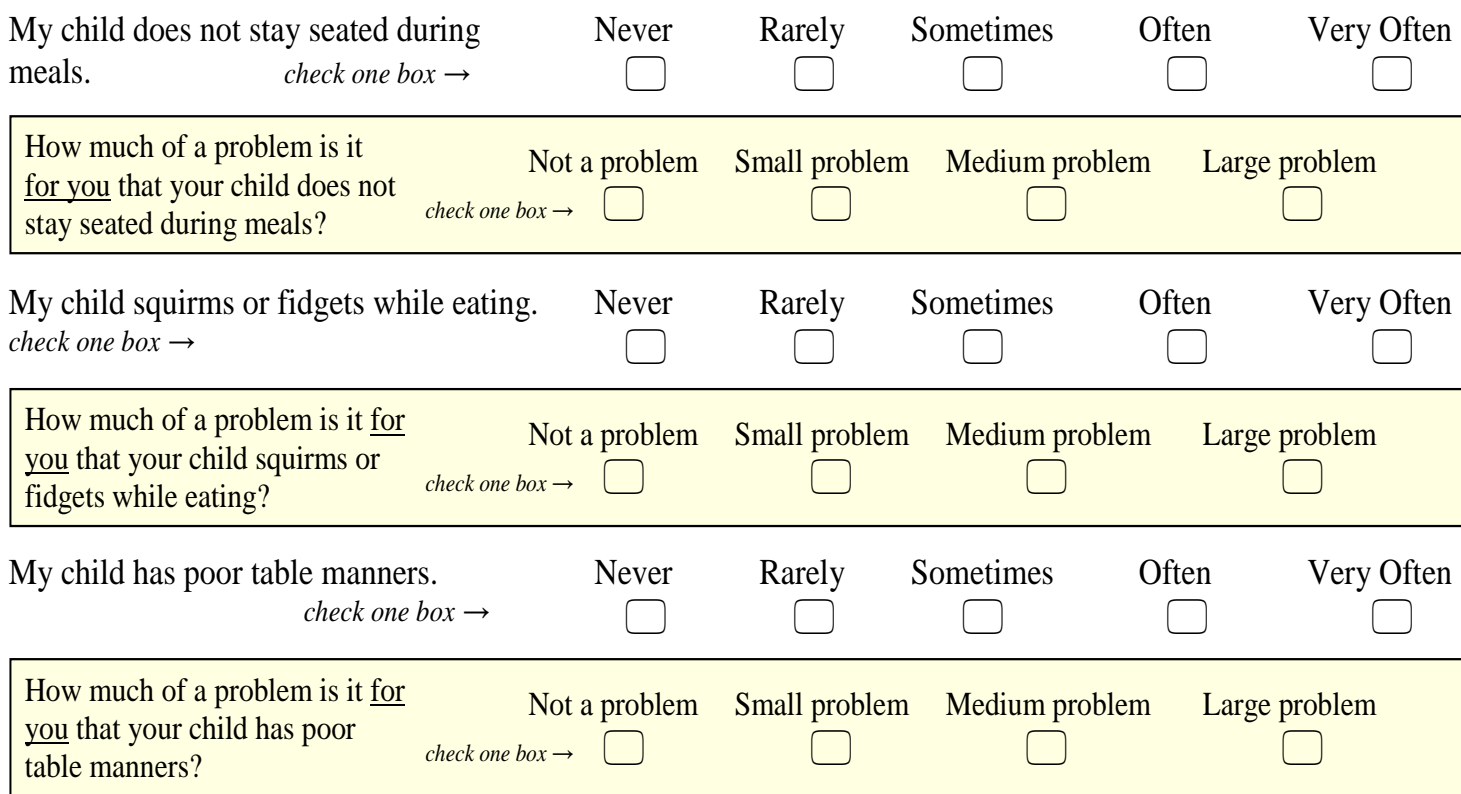

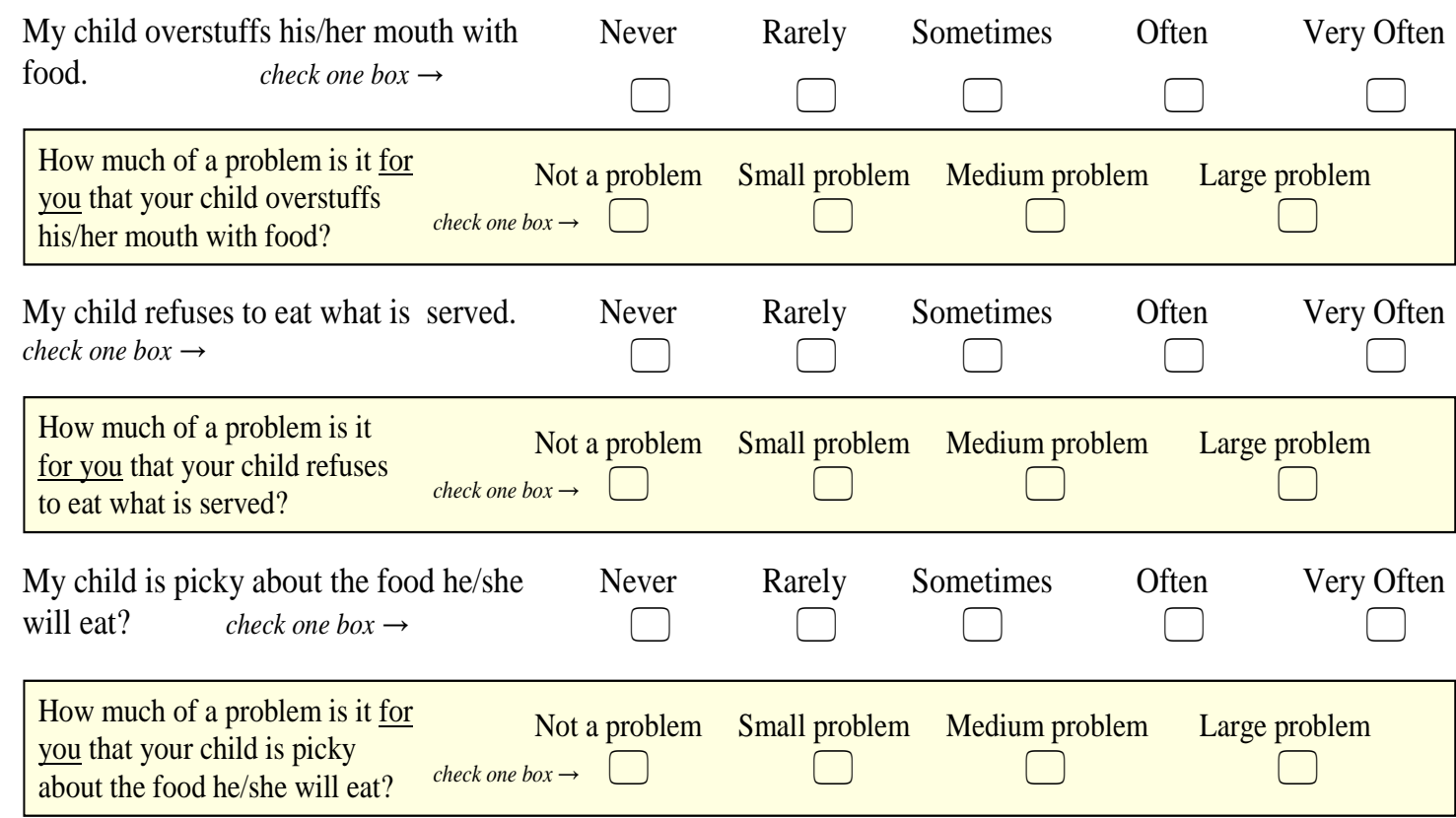


Part C: Parents use many ways to reward and encourage children. For each of the following, please tell us, by checking one box per row, how often the statement describes you and/or your child.

\begin{tabular}{|l|c|c|c|c|c|}
\hline & Never & Rarely & Sometimes & Often & $\begin{array}{c}\text { Very } \\
\text { Often }\end{array}$ \\
\hline $\begin{array}{l}\text { I give my child food to keep him/her quiet when } \\
\text { shopping or traveling. }\end{array}$ & $\square$ & $\square$ & $\square$ & $\square$ & $\square$ \\
\hline $\begin{array}{l}\text { I give my child food to reward him/her for good } \\
\text { behavior. }\end{array}$ & $\square$ & $\square$ & $\square$ & $\square$ & $\square$ \\
\hline $\begin{array}{l}\text { I withhold a food my child likes as a consequence for } \\
\text { bad behavior. }\end{array}$ & $\square$ & $\square$ & $\square$ & $\square$ & $\square$ \\
\hline $\begin{array}{l}\text { My child expects to be given a favorite food as a } \\
\text { reward. }\end{array}$ & $\square$ & $\square$ & $\square$ & $\square$ & $\square$ \\
\hline $\begin{array}{l}\text { I give my child a special food to celebrate an } \\
\text { achievement. }\end{array}$ & $\square$ & $\square$ & $\square$ & $\square$ & $\square$ \\
\hline $\begin{array}{l}\text { I give my child food to persuade him/her to do } \\
\text { something he/she does not really want to do. }\end{array}$ & $\square$ & $\square$ & $\square$ & $\square$ & $\square$ \\
\hline
\end{tabular}

Part D: Some parents have concerns about what their child eats and other parents have few or no concerns about what their child eats. For each of the following, please rate how concerned you are.

\begin{tabular}{|l|c|c|c|c|c|c|}
\hline $\begin{array}{l}I \quad \text { am concerned that my } \\
\text { child... }\end{array}$ & $\begin{array}{c}\text { Not at all } \\
\text { concerned }\end{array}$ & $\begin{array}{c}\text { A little } \\
\text { concerned }\end{array}$ & $\begin{array}{c}\text { Somewhat } \\
\text { concerned }\end{array}$ & $\begin{array}{c}\text { Quite } \\
\text { concerned }\end{array}$ & $\begin{array}{c}\text { Very } \\
\text { concerned }\end{array}$ & $\begin{array}{c}\text { Extremely } \\
\text { concerned }\end{array}$ \\
\hline is not eating enough. & $\square$ & $\square$ & $\square$ & $\square$ & $\square$ & $\square$ \\
\hline is eating too much. & $\square$ & $\square$ & $\square$ & $\square$ & $\square$ & $\square$ \\
\hline is a picky eater & $\square$ & $\square$ & $\square$ & $\square$ & $\square$ & $\square$ \\
\hline eats a lot of junk food. & $\square$ & $\square$ & $\square$ & $\square$ & $\square$ & $\square$ \\
\hline eats only a few types of food. & $\square$ & $\square$ & $\square$ & $\square$ & $\square$ & $\square$ \\
\hline is not getting good nutrition. & $\square$ & $\square$ & $\square$ & $\square$ & $\square$ & $\square$ \\
\hline has poor eating habits. & $\square$ & $\square$ & $\square$ & $\square$ & $\square$ & $\square$ \\
\hline will not try new foods. & $\square$ & $\square$ & $\square$ & $\square$ & $\square$ & $\square$ \\
\hline $\begin{array}{l}\text { is not flexible about what } \\
\text { he/she eats. }\end{array}$ & $\square$ & $\square$ & $\square$ & $\square$ & $\square$ & $\square$ \\
\hline $\begin{array}{l}\text { has food allergies or } \\
\text { intolerances. }\end{array}$ & $\square$ & $\square$ & $\square$ & $\square$ & $\square$ & $\square$ \\
\hline $\begin{array}{l}\text { will eat foods I don't want } \\
\text { him/her to. }\end{array}$ & $\square$ & $\square$ & $\square$ & $\square$ & $\square$ & $\square$ \\
\hline does not eat a variety of foods. & $\square$ & $\square$ & $\square$ & $\square$ & $\square$ & $\square$ \\
\hline eats too much fat. & $\square$ & $\square$ & $\square$ & $\square$ & $\square$ & $\square$ \\
\hline eats too much sugar. & $\square$ & $\square$ & $\square$ & $\square$ & $\square$ & $\square$ \\
\hline does not eat breakfast. & $\square$ & $\square$ & $\square$ & $\square$ & $\square$ & $\square$ \\
\hline does not eat vegetables. & $\square$ & $\square$ & $\square$ & $\square$ & $\square$ & $\square$ \\
\hline does not eat fruits. & $\square$ & $\square$ & $\square$ & $\square$ & $\square$ & $\square$ \\
\hline does not drink milk. & $\square$ & $\square$ & $\square$ & $\square$ & $\square$ & $\square$ \\
\hline does not eat meat. & $\square$ & $\square$ & $\square$ & $\square$ & $\square$ & $\square$ \\
\hline
\end{tabular}

Please turn the page 


\section{Part E.}

If you have a spouse or partner who lives with you, please tell us how much you agree or disagree with the following statements (check one box per row).

\begin{tabular}{|l|c|c|c|c|c|}
\hline & $\begin{array}{c}\text { Strongly } \\
\text { Disagree }\end{array}$ & Disagree & $\begin{array}{c}\text { Neither Agree } \\
\text { nor Disagree }\end{array}$ & Agree & $\begin{array}{c}\text { Strongly } \\
\text { Agree }\end{array}$ \\
\hline $\begin{array}{l}\text { My child's behavior at meals bothers } \\
\text { my spouse/partner. }\end{array}$ & $\square$ & $\square$ & $\square$ & $\square$ & $\square$ \\
\hline $\begin{array}{l}\text { My spouse/partner does not enjoy } \\
\text { eating with my child. }\end{array}$ & $\square$ & $\square$ & $\square$ & $\square$ & $\square$ \\
\hline $\begin{array}{l}\text { My child's mealtime behavior is a } \\
\text { source of stress in my relationship } \\
\text { with my spouse/partner. }\end{array}$ & $\square$ & $\square$ & $\square$ & $\square$ & $\square$ \\
\hline $\begin{array}{l}\text { My child's food preferences } \\
\text { influence what my spouse/partner } \\
\text { eats. }\end{array}$ & $\square$ & $\square$ & $\square$ & $\square$ & $\square$ \\
\hline $\begin{array}{l}\text { My spouse/partner and I have } \\
\text { different expectations about my } \\
\text { child's mealtime behavior. }\end{array}$ & $\square$ & $\square$ & $\square$ & $\square$ & $\square$ \\
\hline
\end{tabular}

If your household contains two or more children, please tell us how much you agree or disagree with the following statements (check one box per row).

\begin{tabular}{|l|c|c|c|c|c|}
\hline & $\begin{array}{c}\text { Strongly } \\
\text { Disagree }\end{array}$ & Disagree & $\begin{array}{c}\text { Neither } \\
\text { Agree nor } \\
\text { Disagree }\end{array}$ & Agree & $\begin{array}{c}\text { Strongly } \\
\text { Agree }\end{array}$ \\
\hline $\begin{array}{l}\text { My child's behavior at meals bothers } \\
\text { the other children in our household. }\end{array}$ & $\square$ & $\square$ & $\square$ & $\square$ & $\square$ \\
\hline $\begin{array}{l}\text { My child's food preferences influence } \\
\text { what other children in our household } \\
\text { eat. }\end{array}$ & $\square$ & $\square$ & $\square$ & $\square$ & $\square$ \\
\hline
\end{tabular}

\section{Thank you.}

\section{Copyright (C) 2008-2012}

The Ohio State University \& The University of Massachusetts

Meals in Our Household was designed to characterize mealtime behaviors and environments of 3- to 11year-old children. Description of reliability and initial validation of the questionnaire has been published. You may reproduce or modify this questionnaire without prior permission with the condition that you provide attribution to the publication (citation below). Meals in Our Household has not been evaluated for use in clinical settings.

Anderson SE, Must A, Curtin C, Bandini LG. Meals in Our Household: Reliability and initial validation of a questionnaire to assess child mealtime behaviors and family mealtime environments. Journal of the Academy of Nutrition and Dietetics 2012;112(2):276-284. 
Food Frequency Questionnaire

\section{Child Food Frequency Questionnaire}

(Adapted from the Harvard Service Food Frequency Questionnaire)

PLEASE MARK OVER THE PAST WEEK HOW OFTEN YOUR CHILD HAS EATEN THE FOODS LISTED IN THE TABLE BELOW (Mark only one option per food)

\begin{tabular}{|c|c|c|c|c|c|c|}
\hline & $\begin{array}{c}\text { Never } \\
- \\
\text { Did Not } \\
\text { Eat }\end{array}$ & $\begin{array}{c}1 \\
\text { Day Per } \\
\text { Week }\end{array}$ & $\begin{array}{c}2-4 \\
\text { Days Per } \\
\text { Week }\end{array}$ & $\begin{array}{c}5-6 \\
\text { Days Per } \\
\text { Week }\end{array}$ & $\begin{array}{c}\text { Once } \\
\text { Every } \\
\text { Day }\end{array}$ & $\begin{array}{c}\text { More Than } \\
\text { Once } \\
\text { Every } \\
\text { Day }\end{array}$ \\
\hline \multicolumn{7}{|c|}{ Beverages } \\
\hline \multicolumn{7}{|c|}{ Soda (not diet) } \\
\hline \multicolumn{7}{|c|}{ Diet Soda } \\
\hline \multicolumn{7}{|c|}{$\begin{array}{l}\text { Fruit Drinks (ex. Hawaiian Punch, Kool } \\
\text { Aid, Lemonade, Sportsdrinks) }\end{array}$} \\
\hline \multicolumn{7}{|c|}{ 100\% Fruit Juice } \\
\hline \multicolumn{7}{|c|}{ Other Juice } \\
\hline \multicolumn{7}{|c|}{ Coffee, Tea } \\
\hline \multicolumn{7}{|c|}{ Dairy Products } \\
\hline \multicolumn{7}{|c|}{ Milk (to drink or in cereal) } \\
\hline \multicolumn{7}{|c|}{ Chocolate Milk } \\
\hline \multicolumn{7}{|c|}{ Alternative Milk (soy, almond, etc.) } \\
\hline \multicolumn{7}{|c|}{ Instant Breakfast Drink } \\
\hline \multicolumn{7}{|l|}{ Yogurt } \\
\hline \multicolumn{7}{|c|}{ Cottage or Ricotta Cheese } \\
\hline \multicolumn{7}{|c|}{ Cheese (plain or on sandwich) } \\
\hline \multicolumn{7}{|c|}{ Cream Cheese } \\
\hline \multicolumn{7}{|c|}{ Protein Sources } \\
\hline \multicolumn{7}{|c|}{ Hamburger, Cheeseburger } \\
\hline \multicolumn{7}{|c|}{ Hot Dog } \\
\hline \multicolumn{7}{|c|}{ Sausage } \\
\hline \multicolumn{7}{|l|}{ Bacon } \\
\hline Eggs & & & & & & \\
\hline
\end{tabular}




\begin{tabular}{|c|c|c|c|c|c|c|}
\hline & $\begin{array}{c}\text { Never } \\
- \\
\text { Did Not } \\
\text { Eat } \\
\end{array}$ & $\begin{array}{c}1 \\
\text { Day } \\
\text { Per } \\
\text { Week } \\
\end{array}$ & $\begin{array}{c}2-4 \\
\text { Days } \\
\text { Per } \\
\text { Week } \\
\end{array}$ & $\begin{array}{c}5-6 \\
\text { Days } \\
\text { Per } \\
\text { Week } \\
\end{array}$ & $\begin{array}{c}\text { Once } \\
\text { Every } \\
\text { Day }\end{array}$ & $\begin{array}{c}\text { More Than } \\
\text { Once } \\
\text { Every } \\
\text { Day } \\
\end{array}$ \\
\hline \multicolumn{7}{|l|}{ Pizza } \\
\hline \multicolumn{7}{|c|}{ Pasta with Meat Sauce } \\
\hline \multicolumn{7}{|c|}{ Meatloaf, Meatballs } \\
\hline \multicolumn{7}{|c|}{$\begin{array}{l}\text { Tacos, Burritos, Fajitas (meat, tofu, } \\
\text { beans) }\end{array}$} \\
\hline \multicolumn{7}{|c|}{ Macaroni and Cheese } \\
\hline \multicolumn{7}{|c|}{ Chicken Nuggets } \\
\hline \multicolumn{7}{|c|}{ Other Chicken, Poultry } \\
\hline \multicolumn{7}{|c|}{ Fish Sticks, Fried Fish } \\
\hline \multicolumn{7}{|c|}{ Canned Fish (tuna, salmon, etc.) } \\
\hline \multicolumn{7}{|l|}{ Other Fish } \\
\hline \multicolumn{7}{|c|}{ Shellfish (shrimp, lobster, etc.) } \\
\hline \multicolumn{7}{|l|}{ Pork, Ham } \\
\hline \multicolumn{7}{|c|}{ Steak, Roast Beef, Lamb } \\
\hline \multicolumn{7}{|c|}{$\begin{array}{l}\text { Lunch Meats (turkey, ham, bologna, } \\
\text { etc.) }\end{array}$} \\
\hline \multicolumn{7}{|c|}{ Peanut Butter, Nut Butter } \\
\hline \multicolumn{7}{|l|}{ Grilled Cheese } \\
\hline \multicolumn{7}{|c|}{ Beans (black, kidney, baked, chili, etc.) } \\
\hline \multicolumn{7}{|c|}{ Organ Meats (liver, etc.) } \\
\hline \multicolumn{7}{|l|}{ Grains } \\
\hline \multicolumn{7}{|l|}{ Cold Cereal } \\
\hline \multicolumn{7}{|c|}{ Hot Cereal (oatmeal, grits, etc.) } \\
\hline \multicolumn{7}{|c|}{ White or Wheat Bread } \\
\hline \multicolumn{7}{|c|}{ English Muffin, Bagel } \\
\hline \multicolumn{7}{|l|}{ Muffin } \\
\hline \multicolumn{7}{|c|}{ Pancakes, Waffles, French Toast } \\
\hline \multicolumn{7}{|l|}{ Cornbread } \\
\hline \multicolumn{7}{|l|}{ Biscuit, Roll } \\
\hline Pita, Flatbread & & & & & & \\
\hline
\end{tabular}




\begin{tabular}{|c|c|c|c|c|c|c|}
\hline & $\begin{array}{c}\text { Never } \\
- \\
\text { Did Not } \\
\text { Eat }\end{array}$ & $\begin{array}{c}1 \\
\text { Day } \\
\text { Per } \\
\text { Week } \\
\end{array}$ & $\begin{array}{c}2-4 \\
\text { Days } \\
\text { Per } \\
\text { Week } \\
\end{array}$ & $\begin{array}{c}5-6 \\
\text { Days } \\
\text { Per } \\
\text { Week } \\
\end{array}$ & $\begin{array}{c}\text { Once } \\
\text { Every } \\
\text { Day }\end{array}$ & $\begin{array}{c}\text { More Than } \\
\text { Once } \\
\text { Every } \\
\text { Day } \\
\end{array}$ \\
\hline \multicolumn{7}{|l|}{ Tortilla } \\
\hline \multicolumn{7}{|c|}{ Crackers } \\
\hline \multicolumn{7}{|c|}{ Rice (white or brown) } \\
\hline \multicolumn{7}{|l|}{ Noodles } \\
\hline \multicolumn{7}{|c|}{ Other Grains (couscous, quinoa, etc.) } \\
\hline \multicolumn{7}{|l|}{ Fruits } \\
\hline \multicolumn{7}{|l|}{ Grapes } \\
\hline \multicolumn{7}{|l|}{ Banana } \\
\hline \multicolumn{7}{|c|}{ Cantaloupe/Melon } \\
\hline \multicolumn{7}{|l|}{ Apple } \\
\hline \multicolumn{7}{|c|}{ Applesauce } \\
\hline \multicolumn{7}{|l|}{ Pear } \\
\hline \multicolumn{7}{|l|}{ Orange } \\
\hline \multicolumn{7}{|c|}{ Grapefruit } \\
\hline \multicolumn{7}{|l|}{ Mango } \\
\hline \multicolumn{7}{|c|}{ Strawberries/Blueberries/Blackberries } \\
\hline \multicolumn{7}{|l|}{ Peach } \\
\hline \multicolumn{7}{|l|}{ Plums } \\
\hline \multicolumn{7}{|c|}{ Pineapple } \\
\hline \multicolumn{7}{|c|}{ Raisins, Other Dried Fruit } \\
\hline \multicolumn{7}{|c|}{ Orange Juice } \\
\hline \multicolumn{7}{|c|}{ Other $100 \%$ Juice } \\
\hline \multicolumn{7}{|c|}{ Vegetables } \\
\hline \multicolumn{7}{|c|}{ Tomatoes/Tomato Sauce } \\
\hline \multicolumn{7}{|l|}{ Peas } \\
\hline \multicolumn{7}{|c|}{ Green Beans } \\
\hline \multicolumn{7}{|l|}{ Corn } \\
\hline Carrots & & & & & & \\
\hline
\end{tabular}




\begin{tabular}{|c|c|c|c|c|c|c|}
\hline & $\begin{array}{c}\text { Never } \\
- \\
\text { Did Not } \\
\text { Eat } \\
\end{array}$ & $\begin{array}{c}1 \\
\text { Day } \\
\text { Per } \\
\text { Week } \\
\end{array}$ & $\begin{array}{c}2-4 \\
\text { Days } \\
\text { Per } \\
\text { Week } \\
\end{array}$ & $\begin{array}{c}5-6 \\
\text { Days } \\
\text { Per } \\
\text { Week } \\
\end{array}$ & $\begin{array}{c}\text { Once } \\
\text { Every } \\
\text { Day }\end{array}$ & $\begin{array}{c}\text { More Than } \\
\text { Once } \\
\text { Every } \\
\text { Day } \\
\end{array}$ \\
\hline \multicolumn{7}{|l|}{ Celery } \\
\hline \multicolumn{7}{|l|}{ Broccoli } \\
\hline \multicolumn{7}{|l|}{ Peppers (any color) } \\
\hline \multicolumn{7}{|l|}{ Lettuce } \\
\hline \multicolumn{7}{|l|}{ Spinach } \\
\hline \multicolumn{7}{|c|}{ Greens (mustard, turnip, kale, etc.) } \\
\hline \multicolumn{7}{|l|}{ Squash } \\
\hline \multicolumn{7}{|l|}{ Zucchini } \\
\hline \multicolumn{7}{|l|}{ Mixed Vegetables } \\
\hline \multicolumn{7}{|l|}{ Sweet Potatoes/Yams } \\
\hline \multicolumn{7}{|l|}{ Cabbage, Cauliflower } \\
\hline \multicolumn{7}{|l|}{ Snack Foods/Desserts } \\
\hline \multicolumn{7}{|l|}{ Chips (potato, corn, etc.) } \\
\hline \multicolumn{7}{|l|}{ Popcorn } \\
\hline \multicolumn{7}{|l|}{ Pretzels } \\
\hline \multicolumn{7}{|l|}{ Peanuts, Other Nuts } \\
\hline \multicolumn{7}{|l|}{ Fruit Snacks, Fruit Roll-Up } \\
\hline \multicolumn{7}{|l|}{ Graham Crackers } \\
\hline \multicolumn{7}{|l|}{ Cheese Crackers } \\
\hline \multicolumn{7}{|l|}{ Poptart, Breakfast Pastry } \\
\hline \multicolumn{7}{|l|}{ Cake, Cupcake, Donut } \\
\hline \multicolumn{7}{|l|}{ Snack Cakes, Twinkies } \\
\hline \multicolumn{7}{|l|}{ Danish, Pastry, Pie } \\
\hline \multicolumn{7}{|l|}{ Cookies, Brownies } \\
\hline \multicolumn{7}{|l|}{ Chocolate or Candy Bar } \\
\hline \multicolumn{7}{|l|}{ Other Candy } \\
\hline \multicolumn{7}{|l|}{ Jello, Pudding } \\
\hline Ice Cream, Frozen Yogurt & & & & & & \\
\hline
\end{tabular}




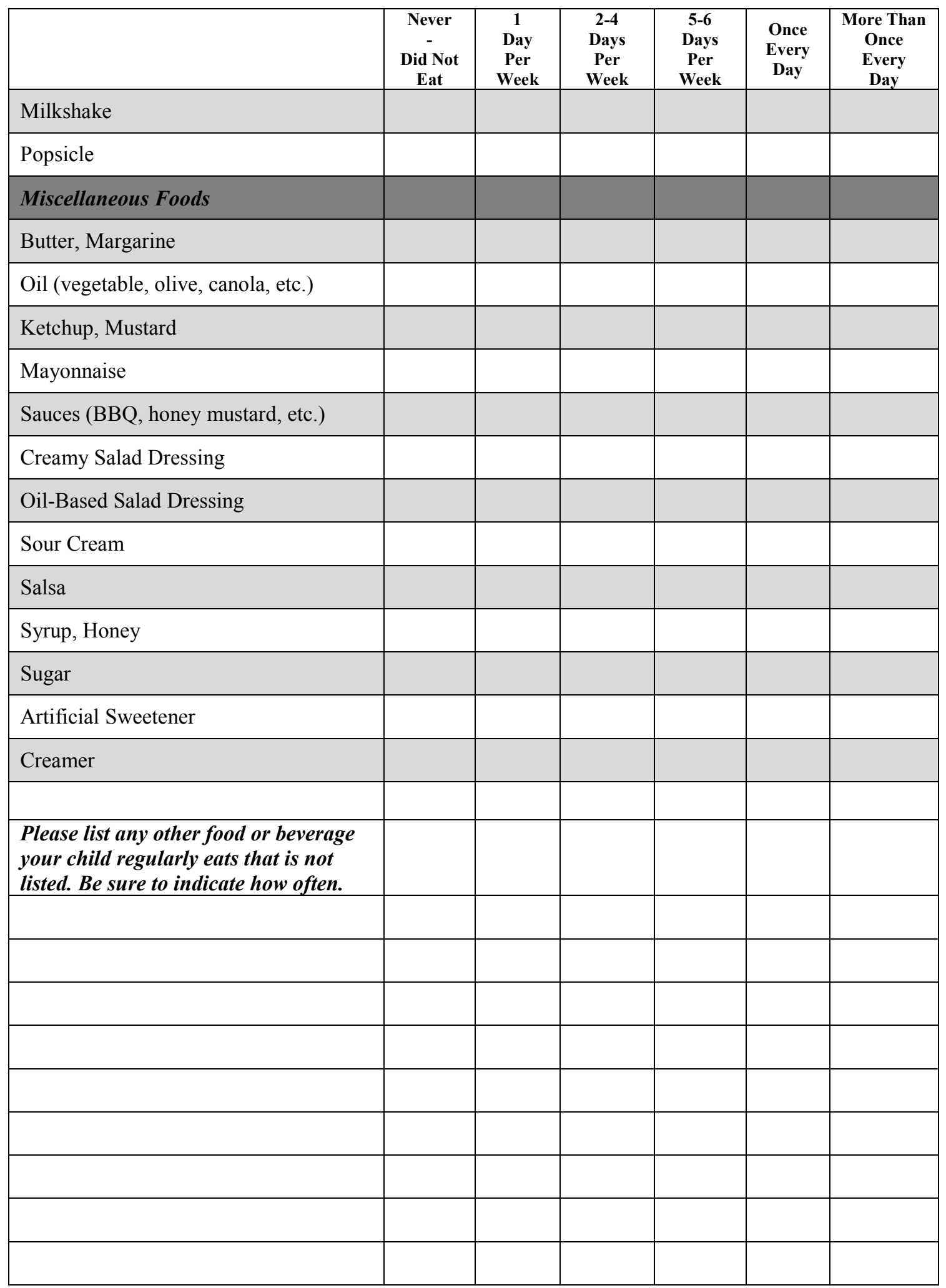

